\title{
Temporal Characteristics of Abyssal Finescale Motions above Rough Bathymetry
}

\author{
JoHn M. TOOLE \\ Woods Hole Oceanographic Institution, Woods Hole, Massachusetts
}

(Manuscript received 25 October 2005, in final form 26 May 2006)

\begin{abstract}
Current-meter data from a two-year mooring within a fracture zone on the western flank of the MidAtlantic Ridge in the South Atlantic Ocean are reported. The mooring, deployed in conjunction with the Brazil Basin Tracer Release Experiment, was placed in the general area where enhanced diapycnal mixing had previously been inferred. The current-meter data characterize the velocity, temperature, shear, and temperature gradient variability as a function of frequency. Energetic velocities and shears were observed at the mooring at a variety of frequencies. In addition to semidiurnal flows, a significant amount of shear variance derived from near-inertial motions, as has been seen in a recent numerical modeling study of tidal-frequency internal wave radiation and wave-wave interaction. At times, a fortnightly modulation of the total superinertial shear variance was indicated in the data, but this signal did not dominate the records. Wave ray tracing indicates that the deeper current meters may have been placed in a shadow zone for locally generated internal tides. At shallower levels, it is suggested that dispersion, wave-wave interaction, and wave breaking effectively obscured the sources of the finescale energy. Average diapycnal diffusivity estimates inferred from a Richardson-number-based parameterization and from observations of temperature inversions at $4648 \mathrm{~m}$ were of the same order of magnitude as those derived from turbulent dissipation estimates and from the rate of diapycnal tracer dispersion. The mooring data thus add additional support to the idea that energetic finescale motions above rough bathymetry support enhanced turbulent diapycnal mixing in these regions.
\end{abstract}

\section{Introduction}

The first two cruises contributing to the Brazil Basin Tracer Release Experiment (BBTRE) documented a striking pattern of turbulent dissipation in the abyssal ocean in which weak turbulent mixing (supporting a diapycnal diffusivity of order $10^{-5} \mathrm{~m}^{2} \mathrm{~s}^{-1}$ ) characterized the water column above smoothly varying areas of the sea floor, and greatly enhanced mixing (larger diffusivities by one to two orders of magnitude extending several hundreds of meters above the bottom) was indicated above rough bathymetry (Polzin et al. 1997; Ledwell et al. 2000; St. Laurent et al. 2001). Internal wave breaking has been proposed as the physical mechanism that supports mixing in the ocean interior (above the turbulent bottom boundary layer) with more energetic wave fields corresponding to greater frequency of wave breaking, more intense turbulence, and enhanced diapycnal mixing (e.g., Garrett and

Corresponding author address: John M. Toole, M.S. \#21, Woods Hole Oceanographic Institution, Woods Hole, MA 02543.

E-mail: jtoole@whoi.edu
Munk 1972; Henyey et al. 1986; Gregg 1989; Polzin et al. 1995). Indeed, greater finescale shear variance [sampled with the free-fall High-Resolution Profiler (HRP)] was observed at stations above the rough flank of the Mid-Atlantic Ridge (MAR) in the Brazil Basin than over the abyssal plain (Polzin 2004a,b). Polzin et al. (1997) hypothesized that the energized internal wave field responsible for the enhanced mixing above the MAR was the consequence of internal wave generation by the barotropic tide flowing over the rough bottom, consistent with rotary vertical wavenumber spectra that indicated a dominance of upgoing internal wave energy (Polzin 2004a). (At the time of that writing, mesoscale flows in this deep, midocean region were thought to be weak in comparison.) Subsequent wavewave interactions were invoked to shift that energy to the small scales that support breaking (Polzin 2004b; MacKinnon and Winters 2003, hereinafter MW) . Tides were further implicated by an apparent fortnightly modulation in profile-averaged kinetic energy dissipation seen in an ensemble of stations from the second BBTRE cruise (Fig. 5 of Ledwell et al. 2000). A similar treatment of the less-extensive HRP data from the first

DOI: $10.1175 / J P O 2988.1$ 

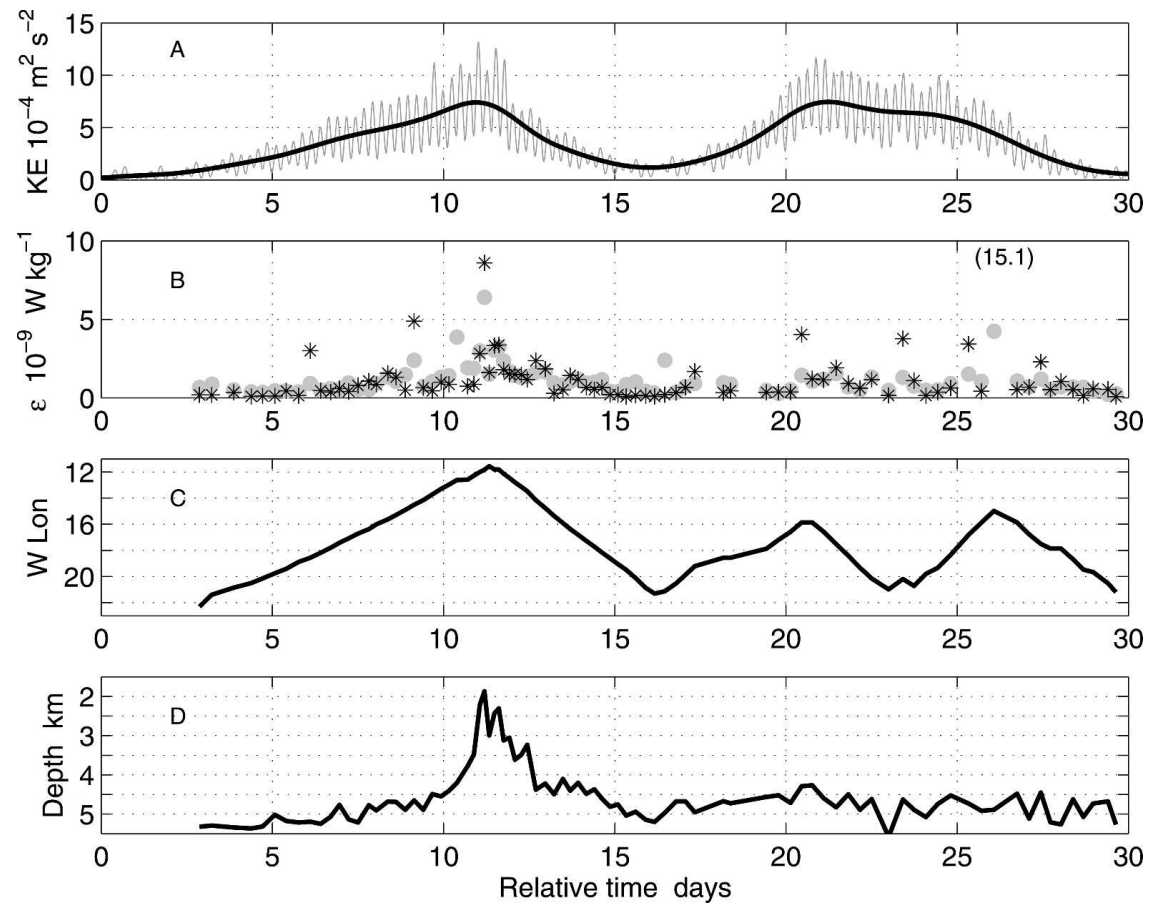

FIG. 1. Observations from the second BBTRE cruise for the period 16 Mar-17 Apr 1997 (plotted in time relative to the starting date): (a) Time series of tidal kinetic energy following the ship derived from the TPXO6.2 model (see text). The thin gray line indicates the raw half-hour samples of the kinetic energy; the thick black curve is a running average (cosine window of width 3.5 days). (b) Estimates of the vertically averaged turbulent kinetic energy dissipation rate (epsilon) from the HRP. Gray dots represent averages over the full water column, while the asterisks mark vertical averages of the dissipation estimates within $1000 \mathrm{~m}$ of the bottom. One of the average dissipation estimates is off the scale of the plot; its value is indicated numerically. All of the HRP profiles used in this figure sampled to within $20 \mathrm{~m}$ of the bottom. (c) The longitude of the ship during the sampling, and (d) the local bottom depth at each station. See Fig. 1a of Ledwell et al. (2000) for a plan view of the stations and local bathymetry.

BBTRE cruise at best only tenuously hints that dissipations vary with the surface tide amplitude.

Although noted by Ledwell et al. (2000), a possible spatial alias in the HRP data from the second BBTRE cruise is often overlooked when this evidence of fortnightly modulation is cited in the literature. The Ledwell et al. depiction is expanded here in Fig. 1. Spring tides (centered on relative days 11 and 22 in Fig. 1a) do appear to correspond to enhanced kinetic energy dissipation, particularly in the bottommost kilometer of the water column (Fig. 1b). However, because of the organization of the spatial survey from which the dissipation data derive, those spring tide HRP profiles tended to be close to the MAR crest in comparison with neap tide stations (Fig. 1c). However, bottom depths at the station sites show a more complex pattern due to the requirements of the tracer sampling that resulted in most of the stations on the second BBTRE cruise being occupied within MAR fracture zones (Fig. 1d). The evidence for fortnightly modulation is not clear-cut.
In addition to tidally generated small-scale waves, enhanced finescale shears could also be the product of near-critical reflection and/or scattering of large-scale internal waves incident on the rough bottom (e.g., Müller and Xu 1992; St. Laurent and Garrett 2002) and/or internal lee wave generation associated with subinertial-frequency currents flowing over the bathymetry (Bell 1975; Thurnherr et al. 2005). St. Laurent and Garrett (2002) argue that low-mode scattering is not an effective source of small-scale wave energy at the MAR, but Polzin (2004b) suggests that it can be significant.

A shortcoming of the BBTRE physical measurements on the first two cruises was a lack of extensive temporal information about the finescale flow field to discriminate between these processes. Two subsequent contributions to the field program addressed this issue. The first, discussed by Duda (2004), consisted of time series of shear magnitude derived from two freedrifting Shearmeter instruments at 1660- and 2850-m 
TABLE 1. Details about the BBTRE current-meter mooring. Key is VACM-T-P: vector currents, temperature, and pressure data; VACM-T: vector currents and temperature data at position $21^{\circ} 37.9^{\prime} \mathrm{S}, 17^{\circ} 48.5^{\prime} \mathrm{W}$; start of record 27 Mar 1998, bottom depth $5115 \mathrm{~m}$; end of record: 3 May 2000; depth of ridge crests north and south of the mooring $\sim 4000 \mathrm{~m}$.

\begin{tabular}{clcl}
\hline $\begin{array}{c}\text { Depth } \\
(\mathrm{m})\end{array}$ & Instrument & $N^{2}\left(10^{-7} \mathrm{~s}^{-2}\right)$ & \multicolumn{1}{c}{ Comments } \\
\hline 2934 & 1 VACM-T-P & & Midpoint $=2947 \mathrm{~m}$ \\
& & 6.3 & No temperature data \\
2959 & 2 VACM-T-P & & Midpoint $=3993 \mathrm{~m}$ \\
3980 & 3 VACM-T & & Bad direction data \\
& & 13.3 & Midpoint $=4648 \mathrm{~m}$ \\
4005 & 4 VACM-T & & \\
4635 & 5 VACM-T & & Intermittent data gaps \\
4660 & 6 VACM-T & 4.7 & \\
5023 & 7 VACM-T & 2.1 & \\
\hline
\end{tabular}

depth. The series lengths were 3 months and 1 year, respectively. The present paper discusses the second contribution: data from a 2-yr-long bottom-anchored mooring deployed on the MAR flank on 26 March 1998 (during a third survey of the tracer distribution). These current-meter data are analyzed here to quantify the frequency distribution of the finescale flow field that is postulated to support the enhanced mixing above the MAR. Companion vertical wavenumber spectra based on HRP observations about the mooring are reported by Polzin (2004a,b). Details of the observations and data reduction are given in the following section, followed by a presentation and discussion of results. A related paper based on these mooring data by Thurnherr et al. (2005) focuses on the low-frequency currents and mixing within the fracture zone, in particular the role of flow over the fracture-spanning transverse faults.

\section{Data}

The BBTRE mooring, equipped with eight vectoraveraging current meters (VACMs, each also logging temperature; Table 1), was placed in the center of a MAR fracture just east of where the tracer was injected (Fig. 2), close to where the Shearmeters were launched. Six of the VACMs were deployed in pairs spaced $25 \mathrm{~m}$ apart in the vertical; the other two spanned the bottommost $\sim 250 \mathrm{~m}$ of the water column. (In the following, the current meters will be referenced by their deployment depth, or in the case of instrument pairs, by the mean depth of the two sensors.) The 25-m spacing was guided by HRP vertical wavenumber shear spectra from the deployment region (see Polzin 2004a, Fig. 5) that exhibit a rolloff in energy density at vertical wavelengths ranging between 50 and $100 \mathrm{~m}$. The VACMs logged data for 767 days before the mooring was recovered on 3 May 2000 (during a fourth and final BBTRE tracer survey). The sea floor in the immediate vicinity of the mooring position $\left(21^{\circ} 37.9^{\prime} \mathrm{S}, 17^{\circ} 48.5^{\prime} \mathrm{W}\right)$ is relatively flat and smooth (the fracture being partially filled with sediment), but the flanks of the ridges bounding the fracture begin just $2-3 \mathrm{~km}$ north and south of the anchor position (Fig. 2). The southern wall of the fracture is steeper and better defined than its northern counterpart. About the longitude of the mooring, the bounding ridges crest around a depth of $4000 \mathrm{~m}$; the mooring was approximately $35 \mathrm{~km}$ from the northern ridge crest and $20 \mathrm{~km}$ from the southern crest. The uppermost pair of current meters was thus approximately $1000 \mathrm{~m}$ above the local bathymetric peaks, the third and fourth VACMs were near the ridge crest level, and the deepest four current meters were within the valley. Ridge and fracture zone bathymetries shoal irregularly to the east. Transverse faulting has resulted in depth variations (peak to saddle) along the ridge crests of $\sim 300 \mathrm{~m}$ with typical horizontal scales (distance between adjacent peaks) of around $4 \mathrm{~km}$. The transverse faulting extends down from the ridges into the adjacent valleys, resulting in bathymetric structures that extend up typically 100-200 m above the sedimented floor of the valleys, sometimes completely spanning the fractures and presumably impeding the flow of the bottommost waters. The closest such features to the mooring were located $6 \mathrm{~km}$ east and $7 \mathrm{~km}$ west of the anchor position. The 3000-m-deep main sill at the head of this fracture zone lies near $12^{\circ} \mathrm{W}$ within the western flank of the MAR rift valley. Deeper sills characterize MAR fracture zones to the south and about the equator through which Brazil Basin bottom waters communicate with the eastern basins of the South Atlantic Ocean.

The VACMs on the mooring were configured to record vector-averaged current velocity estimates and a discrete temperature measurement every 30 minutes during the deployment. All eight instruments recorded data for the full 767 days of the deployment, but no usable temperature data were obtained from the instrument at 2959-m depth, and the flow direction estimates from the meter at $4005 \mathrm{~m}$ are suspect (but speed appears good). The dataset is thus limited to vector shear estimates across 25-m depth from two levels, and strain estimates (vertical derivative of vertical displacement inferred from temperature) from two levels, but coincident shear and strain estimates were obtained from just the one VACM pair centered at 4648-m depth. Pressure sensors interfaced to the shallowest two 
(a)

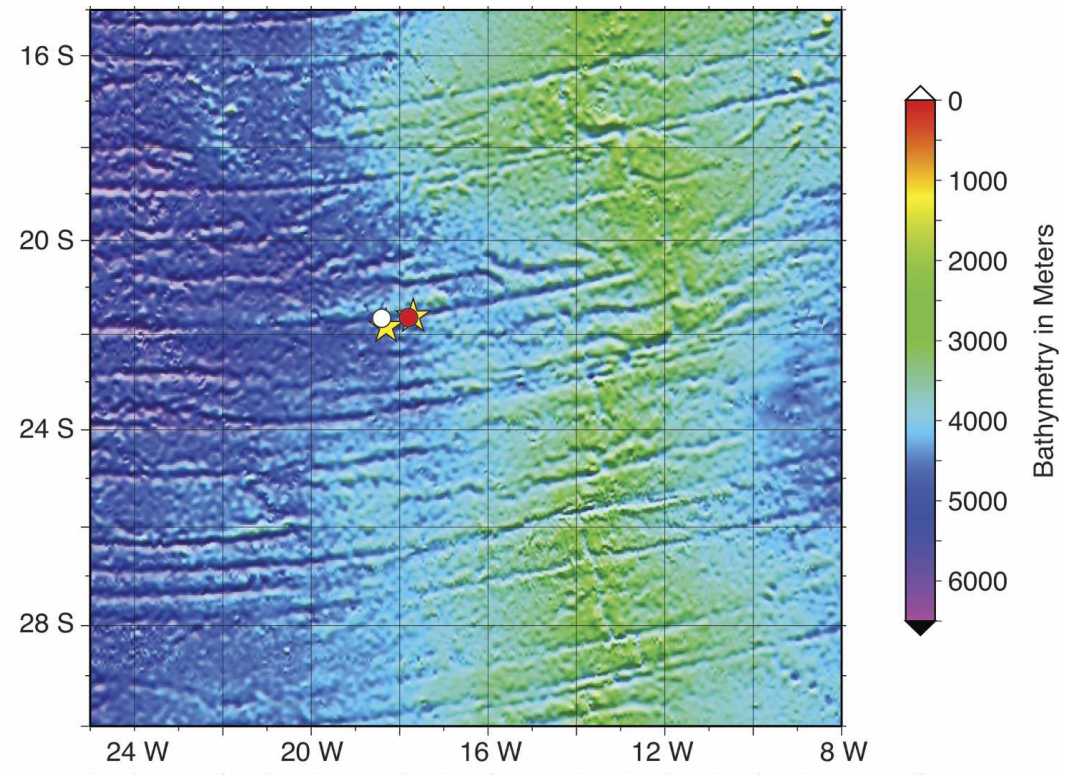

(b)
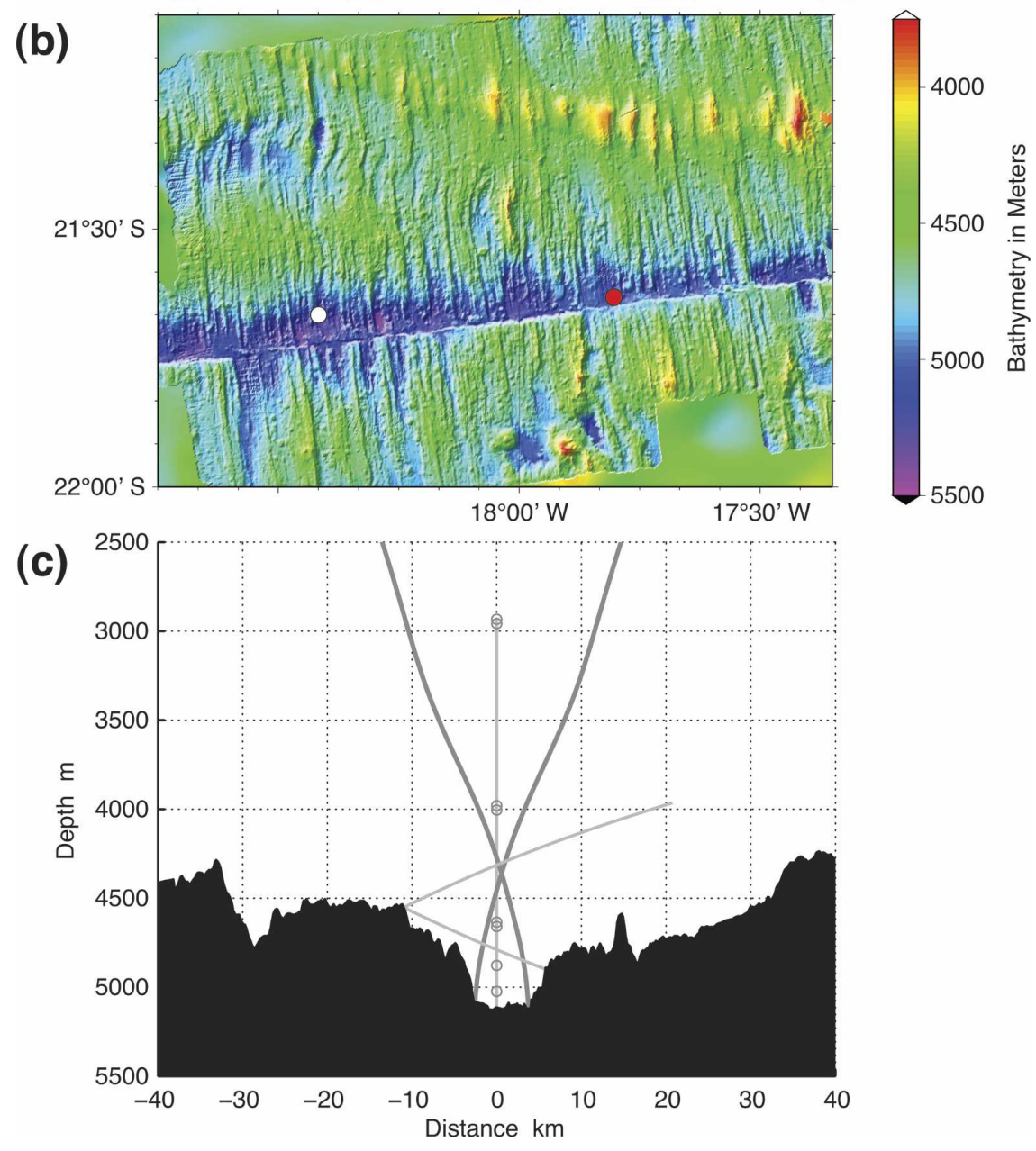

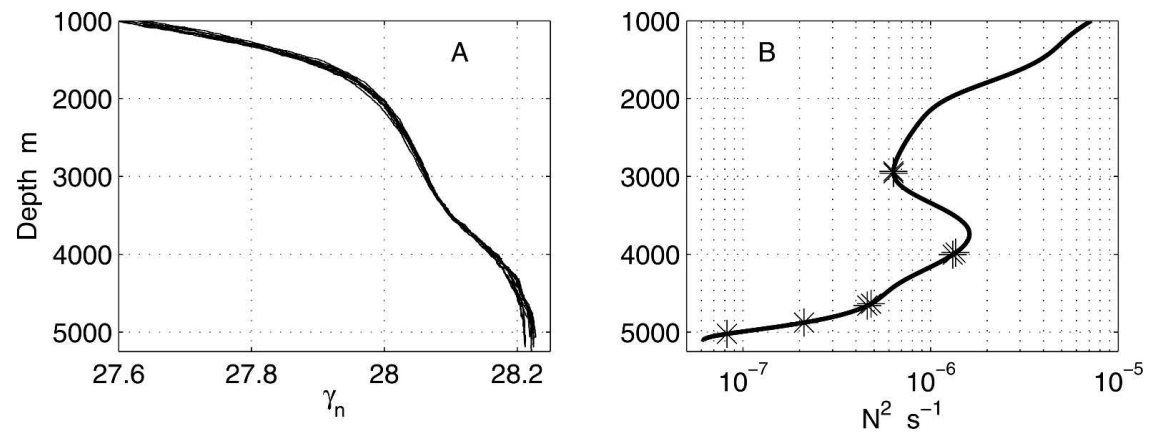

FIG. 3. (a) Ensemble of neutral density profiles vs pressure from the region about the BBTRE mooring and (b) the average squared buoyancy frequency $\left(N^{2}\right)$ profile based on these same station data. The depths of the VACMs on the BBTRE mooring are indicated with asterisks.

VACMs documented only very small variations (differences between minimum and maximum recorded pressures were less than 2 dbar), and so no correction for mooring motion was required. By utilizing conventional Eulerian instrumentation, it is noted that the mooring data were subjected to Doppler shifting and may consequently exhibit signatures of "finestructure contamination" associated with vertical heaving (e.g., Pinkel and Anderson 1997; Alford 2001) and frequency spectral shifting/smearing by horizontal flows.

The present analysis pushes the stated accuracies of the VACM. (The following accuracy estimates were provided by N. Hogg and S. Worrilow 2005, personal communications.) The thermistors used in the VACMs to sense temperature are calibrated in the laboratory to an accuracy of $3 \mathrm{~m}^{\circ} \mathrm{C}$. The overall temperature uncertainty of the system (including the sensing/digitizing electronics) is quoted to be $5 \mathrm{~m}^{\circ} \mathrm{C}$. The least count of the VACM compass is $2.8^{\circ}$; the uncertainty of the derived velocity direction is said to be approximately $5^{\circ}$. The accuracy of the VACM speed estimates when currents are above the rotor stall speed (times when current speed is not sufficient to overcome rotor bearing static friction: $\sim 1.4 \mathrm{~cm} \mathrm{~s}^{-1}$ ) is quoted as $\sim 1 \mathrm{~cm} \mathrm{~s}^{-1}$. Error in the velocity difference between two VACMs appears to be smaller.
Even though the mooring site was in the deep ocean, rotor stall was rare; currents fell below $1.4 \mathrm{~cm} \mathrm{~s}^{-1}$ less than $1 \%$ of the time. These (typically hourlong) periods (at worst case 1 or 2 times per day) corresponded to times when the high-frequency (e.g., tidal) velocity opposed the low-frequency flow. Vector velocity was linearly interpolated through these low-speed intervals prior to analysis. The deepest VACM suffered a data tape advance problem that resulted in more extensive gaps that total $24 \%$ of the record. These gaps were typically $1-6 \mathrm{~h}$ in length and occurred $1-2$ times per day. Linear interpolation was also used to fill these intervals. The high-frequency signals in this record were consequently treated with caution.

A reference potential temperature-salinity relationship and buoyancy frequency profile (Fig. 3) were constructed from CTD profiles made about the mooring site during BBTRE. The temperature-salinity relationship at potential temperatures $(\Theta)$ below $\sim 2.25^{\circ} \mathrm{C}$ (approximately $3300-\mathrm{m}$ depth) appeared stable within the accuracy of our water samples (variations of 0.005 psu at a given temperature, with the slope of the $\Theta-S$ curves indistinguishable among the 4 years). A mean $\Theta-S$ relationship based on these data was used together with VACM depths [converted to pressure using Saunders (1981)] to infer salinity and potential temperature

$\leftarrow$

FIG. 2. Bathymetry of the eastern Brazil Basin. (a) The general region of the Brazil Basin Tracer Release Experiment based on the data of Smith and Sandwell (1997). The red dot marks the mooring location, the white dot is the BBTRE tracer injection area, and the yellow stars show the deployment positions of Shearmeters (Duda 2004). (b) Derived from a multibeam echo sounder survey in April 2000 and focusing on the region about the current-meter mooring (site marked with red dot; the tracer injection site is indicated with a white dot). Note that different color scales were used in the two panels: the top panel was "illuminated" from the north and the lower panel from the northwest in order to highlight the ridge/valley structures and transverse faulting, respectively. (c) Bottom depth profile running perpendicular to the axis of the fracture zone in which the mooring was deployed. Distances are relative to the mooring position with positive values to the north. The locations of the mooring and the individual current meters are indicated. The dark and light gray curves show representative ray trajectories for internal waves at semidiurnal and near-inertial (1.05f) frequency. 
time series from the VACM temperature data. Buoyancy frequency time series were then derived for the functional VACM pairs. The mean buoyancy frequency squared, $N^{2}$, profile at the mooring site (Fig. 3) decreases with depth to $\sim 3000 \mathrm{~m}$, attains a local (weak) maximum at the boundary between North Atlantic Deep Water and Antarctic Bottom Water $\left(\sim 2^{\circ} \mathrm{C}\right.$, 3750-m depth), then falls to near zero at the valley floor.

To account for low-frequency variations in the stratification, vertical displacements about the two VACM pairs that returned good temperature data were derived from a combination of low-pass and high-pass filtered potential temperature records $\left(\langle\Theta\rangle\right.$ and $\Theta^{\prime}$, respectively) as $\zeta=\Theta^{\prime}(-\Delta\langle\Theta\rangle / \Delta z)^{-1}$ where a low-pass-filter cutoff frequency of $1 / 14 \mathrm{cpd}$ was employed and the vertical difference is across the $25-\mathrm{m}$ separation between the paired current meters. Displacements were estimated for each VACM in a pair and strain time series were derived as $\eta=(\Delta \zeta / \Delta z)$.

In addition to the VACM data, current data from a tidal model were analyzed. Barotropic tidal currents for the time interval of the moored observations predicted by the TPXO_6.2 surface-tide model (Egbert et al. 1994; Egbert and Erofeeva 2002) were extracted using data files and instructions obtained from the Web site http://www.coas.oregonstate.edu/research/po/research/ tide/global.html. The full suite of model tidal constituents were used: $M_{2}, S_{2}, N_{2}, K_{2}, K_{1}, O_{1}, P_{1}$, and $Q_{1}$. Model current estimates were derived at the same halfhour time step of the VACMs. Note that the model currents were reported with an estimated bottom depth of $4263 \mathrm{~m}$-a figure more representative of the local ridge crests than the bottom of the valley where the mooring was deployed. The $1 / 4^{\circ}$ resolution of the model does not fully represent the individual narrow fracture zones of the MAR, but their net effect on the surface tide (as manifested by the altimeter observations that the model assimilated) is presumably incorporated in its predictions.

For compatibility with Duda (2004), the observed current-meter spectra were also compared to the GM81 internal wave prescription (Munk 1981). Looking ahead to the analysis of shear (for which there is no analytical model representation), velocity time series at specified buoyancy frequency from depths separated by $25 \mathrm{~m}$ in the vertical were simulated using a (slightly modified) routine provided by T. Duda. The simulated series included the contributions from a random superposition of waves that spanned vertical wavelengths equivalent to modes 1 to 1000 and frequencies between $1.05 f$ and $0.95 \mathrm{~N}$ with amplitudes consistent with the Garrett-Munk (GM) spectral form. Simulated series sample rate and length were matched to the VACM data. Simulated shear series were derived by differencing the velocity estimates from the two depths. The reader is referred to Duda (2004) for model details.

The current-meter data were analyzed in both time and frequency domains. For the former, bandpass filters were applied to investigate shear variability within four frequency intervals. Multipole, recursive Butterworth filters were developed with cutoff frequencies of 1 cycle per 2 days, 1 cycle per $16.7 \mathrm{~h}$, and 1 cycle per 6 $\mathrm{h}$ to partition the velocity records into low-frequency, near-inertial, near-semi-diurnal, and high-frequency motions. As noted above, a 14-day filter was used in the analysis of the VACM temperature data. Running estimates of variance were derived by convolving the squared fields with a 7-day-wide cosine window of unit area. (The filter has a width at half amplitude of 3.5 days.) Frequency spectra were constructed by subdividing the records into 27 sequential 28 -day segments, detrending by least squares fitting, prewhitening, performing the fast Fourier transform, recoloring, estimating power energy densities, and averaging the 27 estimates at each frequency. (No frequency averaging was performed.)

\section{Results}

\section{a. Low-frequency motions}

The characteristics of the subinertial currents sampled at the mooring were discussed by Thurnherr et al. (2005); for context here, time series of low-passed velocity and temperature data are shown in Figs. 4 and 5. The current-meter records fall naturally into two groups: VACMs in the depth interval $2934-4005 \mathrm{~m}$ and those at and below $4635 \mathrm{~m}$. The low-frequency flows and temperature variations of the first group (from depths at and above the crests of the local bathymetry) were not correlated with those within the valley. The record mean velocity about $2947 \mathrm{~m}$ was just $0.4 \mathrm{~cm} \mathrm{~s}^{-1}$ directed to the NNE and not significantly different from zero. However, within the valley the record-mean currents were strongly eastward (toward the head of the valley). The record-mean zonal components from the VACMs at 4635-, 4660-, and 4878-m depth were indistinguishable at the $95 \%$ confidence interval; their combined average is $1.7 \mathrm{~cm} \mathrm{~s}^{-1}$ to the east; speeds sampled at the bottommost meter were slightly less. (Record-mean eastward velocity was $1.2 \mathrm{~cm} \mathrm{~s}^{-1}$. The mean meridional velocity estimates from those four VACMs were not significantly different from zero.) These mean velocity estimates are about a factor of 5 larger than St. Laurent et al. (2001) inferred from a heat budget for the waters within the fracture zone. The 

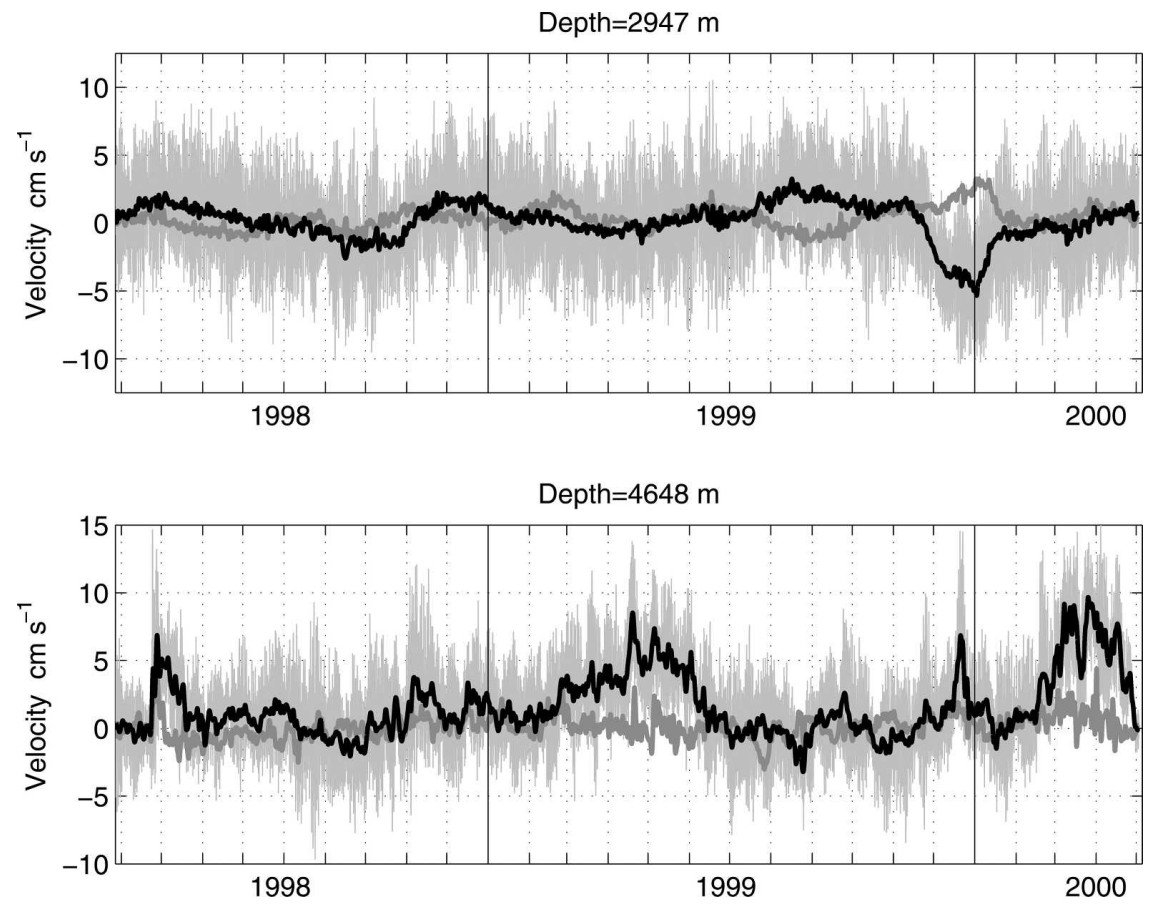

FIG. 4. Velocity time series about 2947 and $4648 \mathrm{~m}$ plotted vs calendar year. Raw, half-hour estimates of the zonal component are shown in light gray; the thick black and gray lines are the low-passed zonal and meridional components, respectively. The low-passed data from the two VACMs about each level were averaged to produce this figure.

mean velocities estimated in the valley are influenced by four episodes of quite strong eastward flow over the 2-yr record (Fig. 4). Excluding these periods of strong flows (times when the low-frequency flow was greater than $3.5 \mathrm{~cm} \mathrm{~s}^{-1}$ ) still yields a significant eastward mean of $0.7 \mathrm{~cm} \mathrm{~s}^{-1}$. Thurnherr et al. (2005) speculate about these surprisingly strong low-frequency currents in the valley but no definitive explanation for them has as yet been offered.

The stratification of the waters above the bounding ridge crests was relatively stable in time. The lowpassed potential temperature gradient about $3993 \mathrm{~m}$ (Fig. 6) and $N^{2}$ ranged by just a factor of 2 during the deployment. In contrast, large stratification variations were observed within the valley: maximum $N^{2}$ and lowfrequency temperature gradient about $4648 \mathrm{~m}$ exceeded the minimum observed values by a factor of 12 (Fig. 7). Referenced with the mean temperature profile, the $0.1^{\circ} \mathrm{C}$ range in low-passed temperature implies vertical displacements of $\sim 150 \mathrm{~m}$ peak to peak; vertical displacements of the mean $N^{2}$ profile (Fig. 3) of this size induce stratification changes of only a factor of 4 . Thus the observed $N^{2}$ variations about $4648 \mathrm{~m}$ appear inconsistent with simple vertical heaving of the time-mean profile. At long periods there is indication that the velocity and temperature variations are in quadrature: coldest temperatures about $4648 \mathrm{~m}$ were observed at the end of periods of sustained eastward flow. The progressive vector diagrams derived with the valley velocity perturbations from the record means exhibited zonal excursions of $\pm 100 \mathrm{~km}$ around annual period (not shown). Zonal displacements of this magnitude of the along-valley horizontal temperature gradient (sampled during the 1997 tracer survey cruise) would give rise to $\pm 0.05^{\circ} \mathrm{C}$ temperature variations, consistent in amplitude and phase with the observed temperature variations. However, the synoptic valley section found weaker stratification as well as warmer temperature with distance east. No such correlation between temperature and temperature gradient is evident in the valley VACM data. Evidently the long-period temperature and stratification changes within the valley are more complicated than those induced by simple kinematic horizontal or vertical advection of the mean fields.

Several aspects of the low-frequency flow and stratification may influence the finescale motions. The vertical shear of the low-frequency flow was generally small in comparison to that of the superinertial motions, but on occasion it did measurably contribute to the total shear (see below). In addition to the possible hydraulic behavior discussed by Thurnherr et al. (2005), 

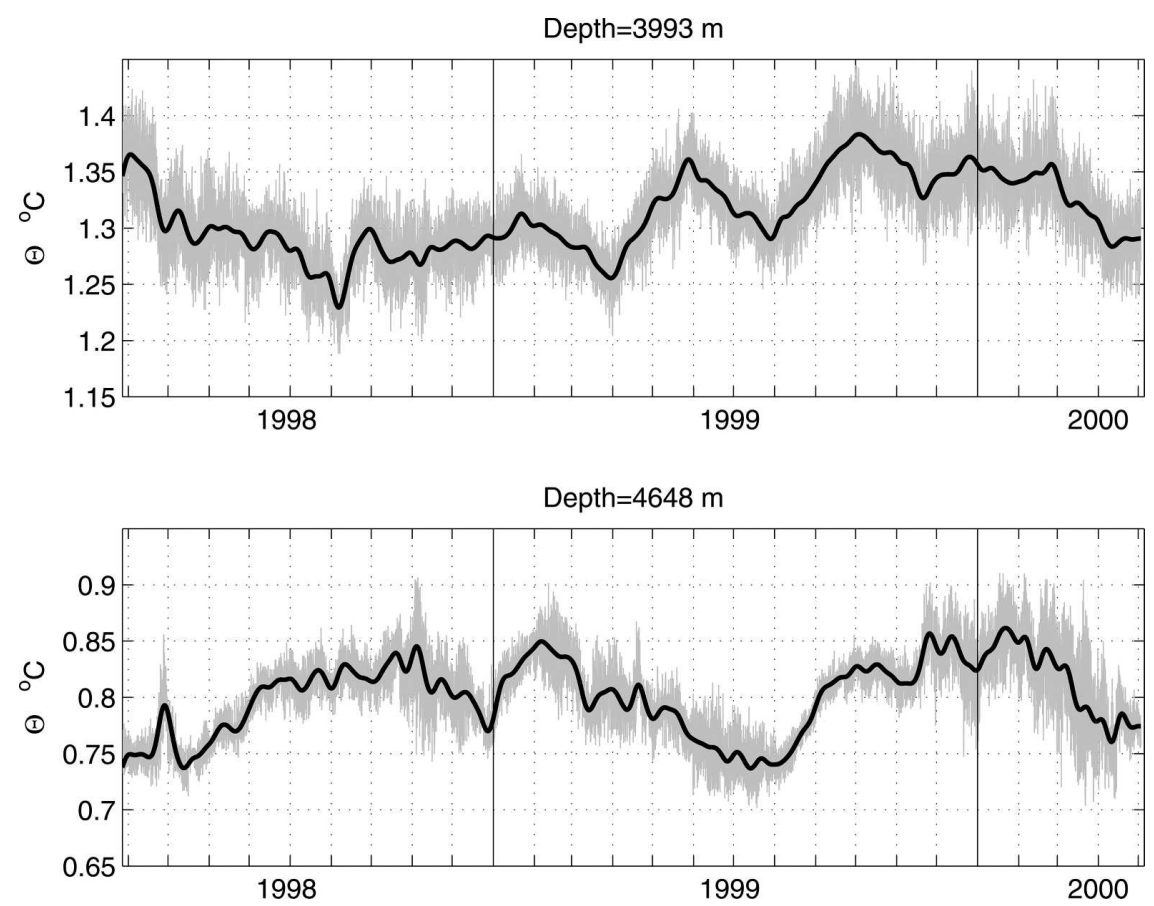

FIG. 5. Potential temperature time series about 3993 and $4648 \mathrm{~m}$ plotted vs calendar year. Raw, half-hour estimates are shown in light gray while the thick black lines are the low-passed data. The low-passed data from the two VACMs about each level were averaged to produce this figure.

near-bottom currents responding to bottom irregularities might generate internal lee waves that would contribute to the finescale shear field. In a steady flow, lee waves appear at zero frequency in a frame fixed to the bottom, but time-varying currents could shift the motions to higher Eulerian frequency. Shear in the lowfrequency flow could also be important to the vertical propagation of lee waves. At several times during the 2-yr deployment when strong near-bottom flow was observed, the velocity changed sign at some higher elevation (Fig. 4). Depths of zero current velocity are critical layers for lee waves (which, by definition, have zero horizontal phase velocity). As bottom-generated waves approach such a level, we expect the wave vector to rotate toward horizontal, vertical wavelengths to decrease, and shears to increase, possibly leading to wave breaking. Last, we note that the amplitude of internal wave motions will tend to scale with stratification (larger horizontal velocities and shears and smaller vertical displacements are expected at larger stratification).

\section{b. Superinertial velocity and displacement}

Visually, the raw velocity (Fig. 4) and temperature (Fig. 5) records exhibit energetic superinertial variability with amplitudes comparable to those of the low-fre- quency motions. Remarkably good agreement was found between the observed tidal-band currents and those predicted by the TPXO_6.2 surface-tide model. Correlations around 0.9 at zero lag are obtained between the tidal-band current components about $2947 \mathrm{~m}$ and the model currents, with observed tidal-band and model record-mean kinetic energies of 3.8 and $3.5 \mathrm{~cm}^{2} \mathrm{~s}^{-2}$, respectively. Comparable tidal-band kinetic energy was observed at $3980 \mathrm{~m}$. Weaker semidiurnal currents were sampled about $4648 \mathrm{~m}$ (the record-mean tidal-band kinetic energy about this depth is $2.8 \mathrm{~cm}^{2} \mathrm{~s}^{-2}$ ), but somewhat stronger currents were observed at 4878 and 5023 m. (Averaged tidal-band kinetic energies for the VACMs at these levels are 4.6 and $4.1 \mathrm{~cm}^{2} \mathrm{~s}^{-2}$, respectively. Recall that the VACM record from $5023 \mathrm{~m}$ was gappy.) The semidiurnal currents at the deepest two instruments tended to lead the shallower currents (and the model prediction) by about $2 \mathrm{~h}$.

Frequency spectra of the VACM velocity data about 4648-m depth (Fig. 8a) show narrow energy density peaks at $M_{2}$ and $S_{2}(\sim 0.08 \mathrm{cph}$, not clearly distinguished on the scale of this figure), a rather broad maximum just above the local inertial frequency $(0.03 \mathrm{cph})$, and smaller peaks at the harmonic frequencies (referring to the combined semidiurnal motions as $\mathrm{SD}$ ) of (SD $-f)$, $(\mathrm{SD}+f)$, and $(2 \times \mathrm{SD})$ above the typical background 

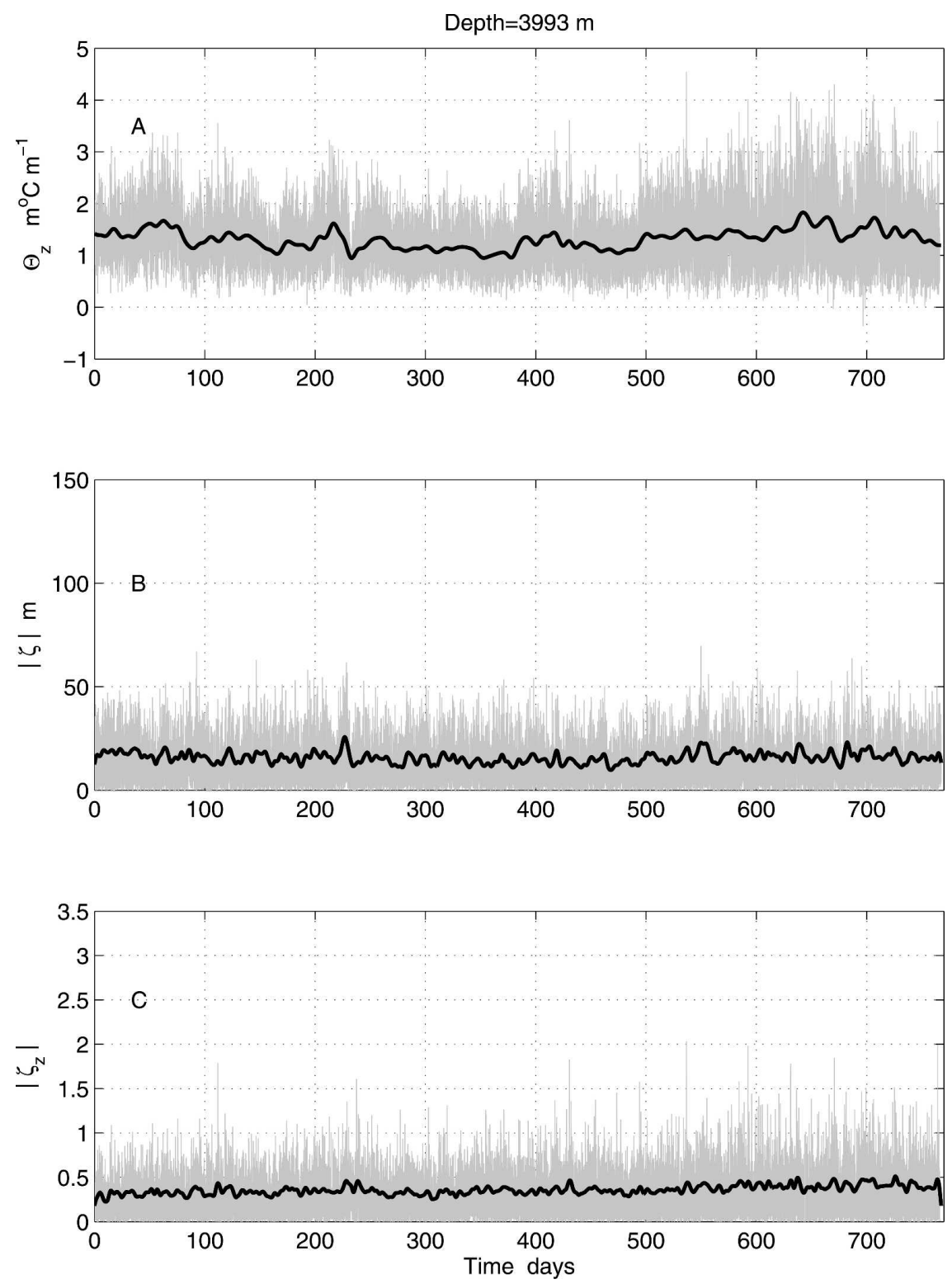

FIG. 6. (a) Potential temperature gradient, (b) absolute value of vertical displacement, and (c) absolute value of the strain time series about $3993 \mathrm{~m}$ plotted relative to the start of the moored record. The raw half-hour estimates are shown in gray, the low-passed values with thick black lines. In (b) the low-passed displacement data have been buoyancy scaled by the time-varying $N^{2}$ derived from the low-passed temperature gradient time series shown in (a). (The raw half-hour displacement data were not buoyancy scaled.) Note that the length of the time axis in this and subsequent figures matches that of Figs. 4 and 5.

distribution that varies with frequency $(\omega)$ as $\omega^{-2}$ up to the buoyancy frequency. The peaks at the inertial-tidal harmonics are possibly artifacts of the Eulerian instrumentation noted earlier. As expected, the near-inertial energy is chiefly in the anticyclonically rotating component; enhanced anticyclonic relative to cyclonic energy density is also observed at semidiurnal frequencies. Approximate equipartitioning is seen at continuum fre- quencies. For frequencies above SD, buoyancy scaling collapses the kinetic energy spectra from 3980 to 4878 $\mathrm{m}$, but scaled kinetic energy densities about $2947 \mathrm{~m}$ are a factor of 2 smaller (Fig. 8b). Conversely, buoyancyscaled kinetic energy densities at near-inertial frequencies were greatest about $2947 \mathrm{~m}$ (factor of 3 greater than the energy density at $3980 \mathrm{~m}$ and about $4648 \mathrm{~m}$ ). At the two deepest VACMs, no inertial peak was ob- 

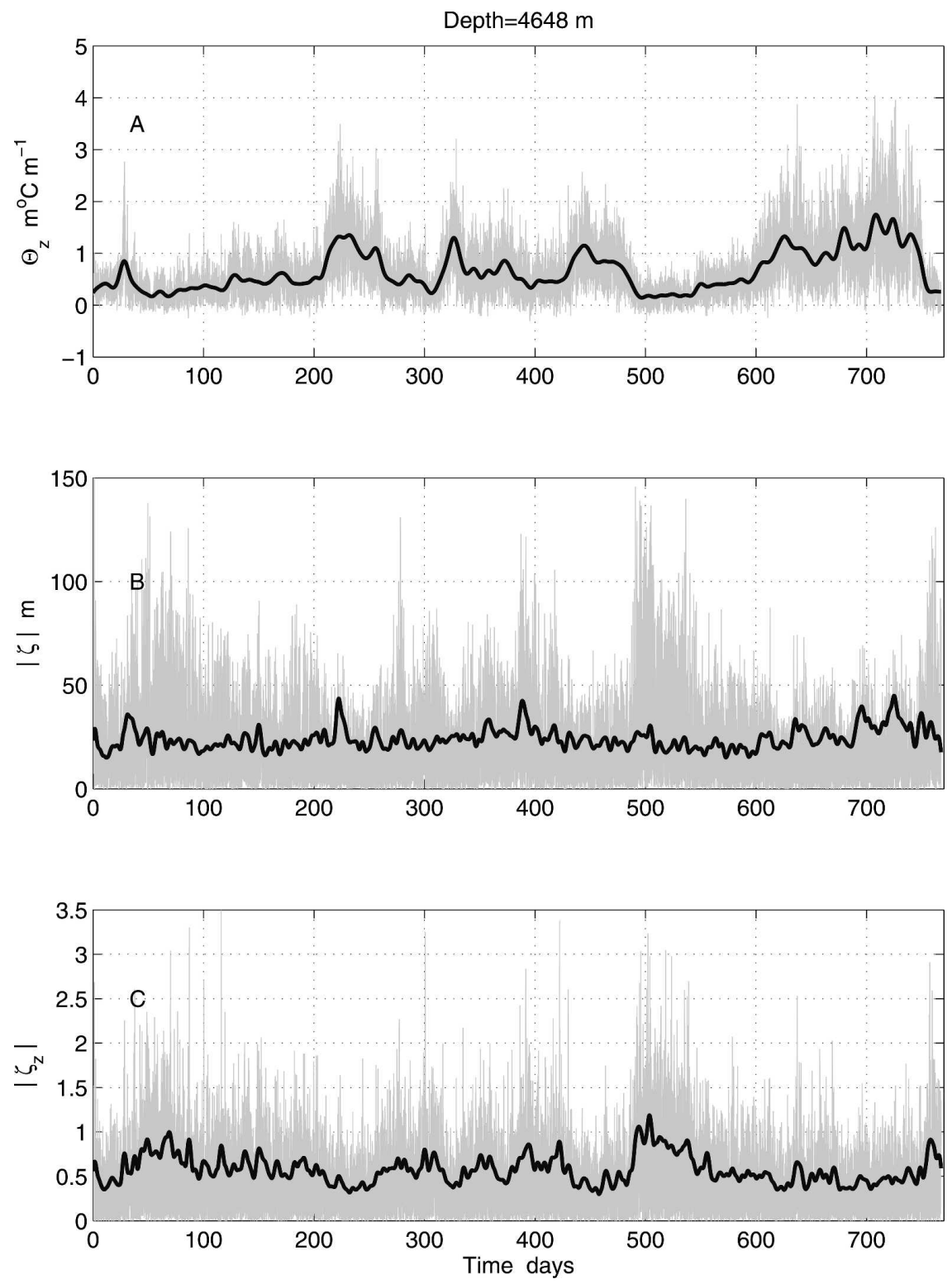

FIG. 7. As in Fig. 6 but for the data about 4648-m depth.

served but, rather, uniform kinetic energy density was obtained between $\sim 1.2 f$ and SD $-f$. Proximity to the sidewalls of the valley may have suppressed the nearinertial motions at these depths, perhaps analogous to Kunze et al.'s (2002) report of reduced inertial currents within Monterey Submarine Canyon. The buoyancyscaled kinetic energy spectrum for $5023 \mathrm{~m}$ is shaped much like that at $4878 \mathrm{~m}$ for frequencies between $f$ and $2 \times \mathrm{SD}$ but the level is approximately 2.5 times as large (not shown). It is not known if this is real or a reflection of error in the mean $N^{2}$ used to scale the spectra from these levels.

Apart from the semidiurnal peak and associated har- monics, and the slight deficit of energy density between $f$ and $M_{2}$ discussed by Levine (2002), the anticyclonic rotary spectrum about $4648 \mathrm{~m}$ is reasonably well represented by the GM81 model (Fig. 8a). However, the observed cyclonic kinetic energy density exceeds the prescription by a factor of 3-5 about the inertial frequency. Due to this difference and the absence of tides in the GM model, the observed internal-wave-band kinetic energy about $4648 \mathrm{~m}$ exceeds the GM81 prediction by $65 \%\left(4.8\right.$ versus $\left.2.9 \times 10^{-4} \mathrm{~m}^{2} \mathrm{~s}^{-2}\right)$.

High-frequency (periods shorter than 14 days) vertical displacements estimated about $3993 \mathrm{~m}$ (close to the depth of the local ridge crests) were reasonably station- 

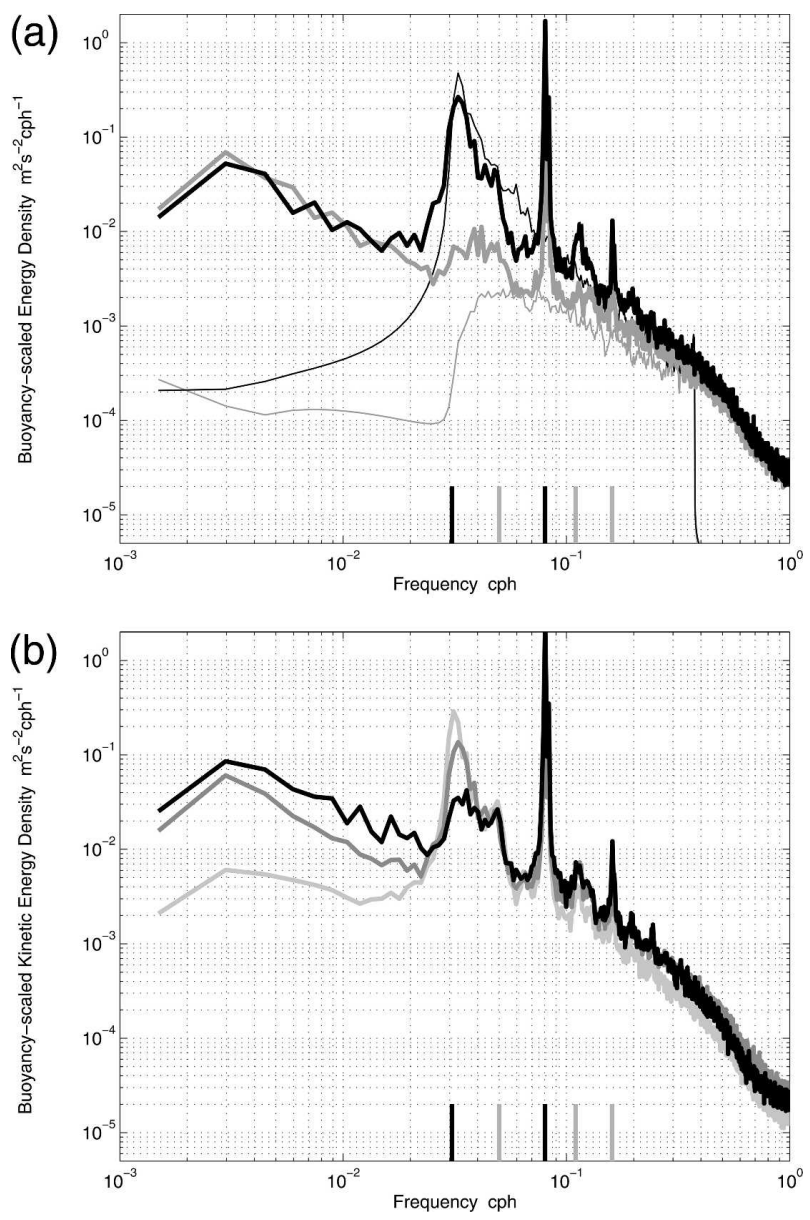

FIG. 8. (a) Rotary velocity spectra about 4648-m depth, buoyancy scaled to $3 \mathrm{cph}$ using the mean $N^{2}$ for this level. The thick black and gray curves are the anticyclonic and cyclonic components, respectively. The thin black and gray curves are the corresponding GM81 prescriptions based on simulated time series for this depth that were analyzed identically to the VACM data. The finite resolution of the model is responsible for the noise in the model spectra. The detrending operation (same as was applied to the VACM data) leaked some of the superinertial energy to frequencies below $f$. In this and subsequent spectral plots, the black bars at the bottom of the figure mark the local inertial and semidiurnal (SD) frequencies while the gray bars indicate the frequencies $\mathrm{SD}-f, \mathrm{SD}+f$, and $2 \times \mathrm{SD}$. (b) The buoyancy-scaled kinetic energy spectra based on data about 2947 (light gray), 4693 (dark gray), and 4878 (black) $\mathrm{m}$.

ary throughout the deployment (Fig. 6b). The standard deviation of the estimated vertical displacements at that level is $16 \mathrm{~m}$ with peak values around $50 \mathrm{~m}$. In contrast, below the ridge crests about $4648 \mathrm{~m}$, the amplitude of the vertical displacements was highly variable. At times, displacements attained amplitudes near $150 \mathrm{~m}$ and at other times less than $50 \mathrm{~m}$ (Fig. 7b); the standard deviation of the raw displacement time series about this depth is $28 \mathrm{~m}$. Some of this amplitude variation is as-

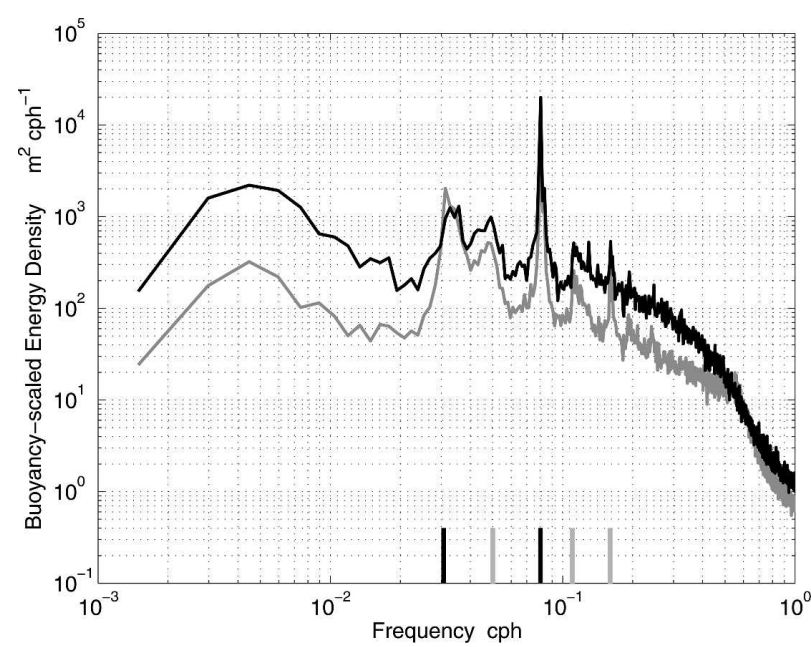

FIG. 9. Frequency spectra of vertical displacements that have been buoyancy scaled to $3 \mathrm{cph}$ based on time-mean estimates of $N^{2}$. The gray curve is based on data about 3993-m depth; the black curve is for data about 4648-m depth.

sociated with changes in the stratification; the time series of displacement variance scaled to account for the low-frequency variations in stratification is much more stationary (Fig. 7b). Even after accounting for the difference in mean $N^{2}$ between 3993 and $4648 \mathrm{~m}$, vertical displacements were more energetic within the valley than above the bounding ridge crests. Scaling to a reference buoyancy frequency of $3 \mathrm{cph}$, the standard deviation of the vertical displacements about 3993 is $7.5 \mathrm{~m}$ whereas about $4648 \mathrm{~m}$ it is $11.6 \mathrm{~m}$. The displacement energy density enhancement at depth in the internal wave band is seen at all frequencies between $\sim 1.3 f$ and $N$ (Fig. 9). Similar to the velocity spectra, peaks in displacement energy density are seen about the inertial and semidiurnal frequencies and their harmonics.

In the time domain, rotation of the velocity vector with depth is indicative of the direction of internal wave vertical energy propagation (Leeman and Sanford 1975). In the Southern Hemisphere, counterclockwise rotation with depth denotes downward energy propagation. Turning of inertial-band currents about 2947 and $4648 \mathrm{~m}$ were examined in both time and frequency domains. In the former, the differences in near-inertial current directions over the $25-\mathrm{m}$ depth separations between VACM pairs were estimated from the bandpassed data. On average, the near-inertial currents about $2947-m$ depth turned 0.13 radians clockwise with depth, a direction difference significantly different from zero at the $95 \%$ confidence level. In contrast, about $4648 \mathrm{~m}$, the near-inertial currents on average turned counterclockwise with depth (0.18 radians over $25 \mathrm{~m}$, also significantly nonzero). Inferred vertical wave- 


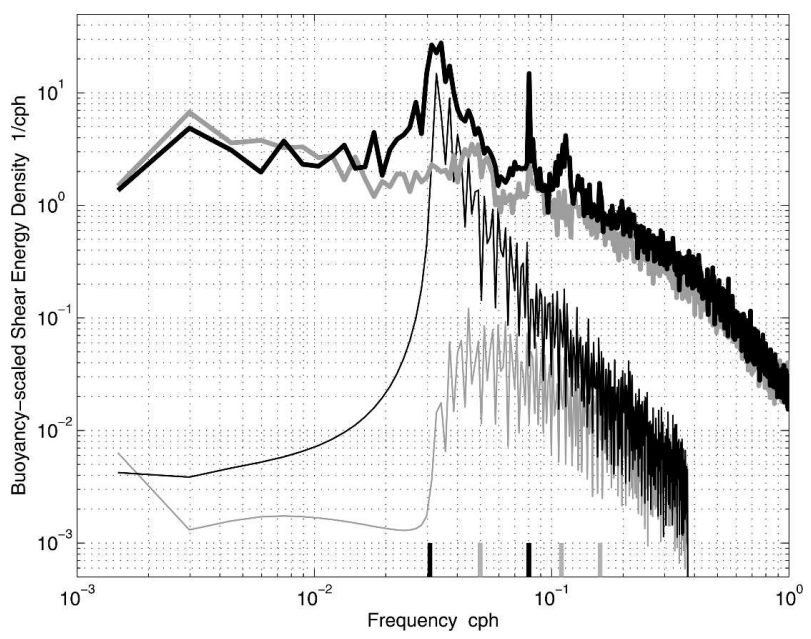

FIG. 10. Rotary shear spectra about 4648-m depth normalized by the time mean $N^{2}$ from this level. The thick black and gray lines correspond to the anticyclonic and cyclonic components, respectively. Also shown with thin lines are the GM81 predictions based on simulated time series for this depth that were analyzed identically to the VACM data. The finite resolution of the model is responsible for the noise in the model spectra.

lengths (distance required for a $2 \pi$ rotation) are 1207 and $872 \mathrm{~m}$, respectively. These mean direction differences are comparable to the VACM compass uncertainty, but the averaging done to produce these direction difference estimates is expected to greatly reduce the statistical uncertainty. Equivalent to the direction difference analysis, a coherence and phase calculation in the frequency domain for the cyclonically rotating velocity component obtained significant, high coherence $(0.95,0.90)$ with phase lags of -0.12 and +0.27 radians for the data about 2947 and $4648 \mathrm{~m}$ respectively for frequencies between 0.03 and $0.04 \mathrm{cph}$. These phase lags across the $25-\mathrm{m}$ vertical separation imply wavelengths of 1343 and $572 \mathrm{~m}$ (roughly comparable to the estimates in the time domain). The temporal stability of these estimates was examined by computing average phase between 0.03 and $0.04 \mathrm{cph}$ for successive 28-day blocks of data (27 blocks in total for each series). For the VACM pairs about 2947 and $4648 \mathrm{~m}$, the standard deviation of these 27 phase difference estimates for the anticyclonic components were 0.14 and 0.25 radians, respectively. Assuming each block is independent, the mean phase differences at the two VACM pairs are significantly different from zero and different from each other at the $95 \%$ confidence level. Interpreted in terms of vertical energy propagation, these results indicate a dominance of upgoing near-inertial energy about 2947-m depth and of downgoing energy about $4648 \mathrm{~m}$. Lower coherences $(0.79,0.66)$ with effectively zero average phase difference $(0.09,0.004$ radians $)$

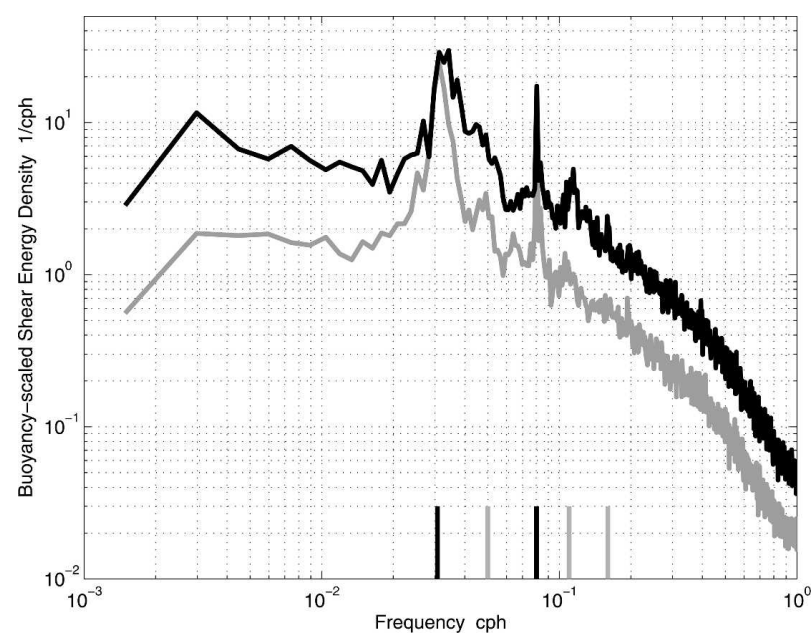

FIG. 11. Shear spectra about 2947- (gray curve) and 4648-m (black curve) depth, each normalized by their respective mean $N^{2}$ values. The average, one-component energy densities are plotted $\left[1 / 2\left(P_{u u}+P_{v v}\right)\right.$ or equivalently $\left.1 / 2\left(P_{\mathrm{cw}}+P_{\mathrm{ccw}}\right)\right]$.

were estimated for the cyclonically rotating, near-inertial currents.

The average direction differences between these pairs of current meters were also derived for the record-mean velocity estimates (0.005 and 0.09 radians, neither significantly different from zero), and for the tidal-band currents (both approximately 0.03 radians on average). Given that little veering of the mean currents would be expected over a $25-\mathrm{m}$ depth interval, the former may be taken as a practical measure of the VACM differential compass accuracy. Absence of significant mean turning across $25-\mathrm{m}$ depth at tidal frequencies could manifest significant contributions by barotropic currents at these frequencies and/or variable internal-wave vertical propagation direction at semidiurnal frequency.

\section{c. Shear and strain}

Rotary shear and strain frequency spectra were constructed by differencing VACM pair data across the $25-\mathrm{m}$ separations. Similar in character to the rotary velocity spectra, the anticyclonic component of the rotary shear spectrum about $4648 \mathrm{~m}$ (Fig. 10) has a broad peak about the inertial frequency, narrow peaks at semidiurnal frequencies, and smaller peaks at the inertial/tide harmonics. Cyclonic and anticyclonic energy densities become comparable at periods of $5 \mathrm{~h}$ and shorter. Shear energy densities of both components exceed those of the GM81 prescription as derived by Duda (2004) at all frequencies. Comparing the buoyancy-scaled shear spectra about 2947 and $4648 \mathrm{~m}$ (Fig. 11), it is evident that shear variance at depth exceeded that at the shal- 


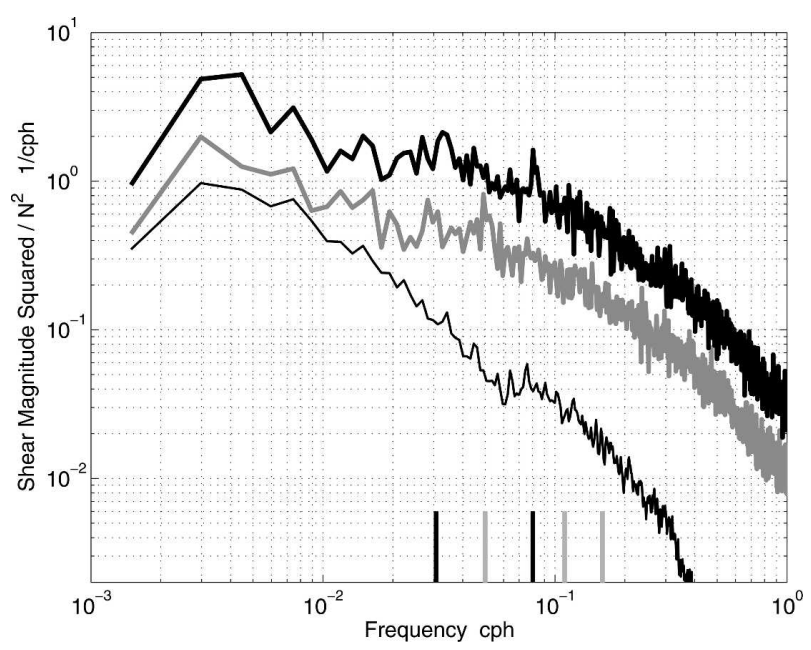

FIG. 12. Frequency spectra of shear magnitude $\left(u_{z}^{2}+v_{z}^{2}\right)$ normalized by time-mean $N^{2}$. The gray curve is based on data about 2947-m depth; the black curve is for $4648 \mathrm{~m}$. The thin line is the corresponding GM81 prescription.

lower level by a factor of 3 at nearly all frequencies. The two exceptions to this are at frequencies near $f$ and SD where the spectral density levels differ by a factor of 2 . Duda's (2004) Shearmeters logged time series of shear magnitude. Frequency spectra of the shear magnitude based on the VACM pairs about 2947 and $4648 \mathrm{~m}$ were constructed for comparison to those data (Fig. 12). The resultant spectra show nearly uniform energy density from periods of 4 days to $10 \mathrm{~h}$, whereas the singlecomponent spectra exhibited peaks at $f, \mathrm{SD}$, and their harmonics. The GM81 prescription for spectral shear magnitude falls as $\omega^{-1}$ through these frequencies. Comparing Figs. 10 and 12 demonstrates that knowing just the shear magnitude makes it difficult to quantify the internal wave frequencies responsible for the shear. (Duda notes that addition of a tilt sensor to Shearmeters would allow vector shear to be determined.) Spectral density levels of shear magnitude about $4648 \mathrm{~m}$ exceed those about $2947 \mathrm{~m}$ at all frequencies by a factor of $\sim 3$. They exceed the GM81 model estimates by a factor of $\sim 4$ at subinertial frequencies, increasing to $\sim 40$ as the buoyancy frequency is approached. The general shape of the shear-magnitude spectra based on the VACM data are similar to those reported by Duda based on Shearmeter data (his Fig. 4). However, the overall levels of the spectra differ: energy densities based on the Shearmeter data from $2850 \mathrm{~m}$ are greater than those for the VACMs about $2947 \mathrm{~m}$ by a factor of $\sim 3$. This difference is believed to be due principally to the vertical separation between measurement levels: $10 \mathrm{~m}$ for the Shearmeters and $25 \mathrm{~m}$ for the VACMs. The GM81 estimates of shear magnitude spectral den-

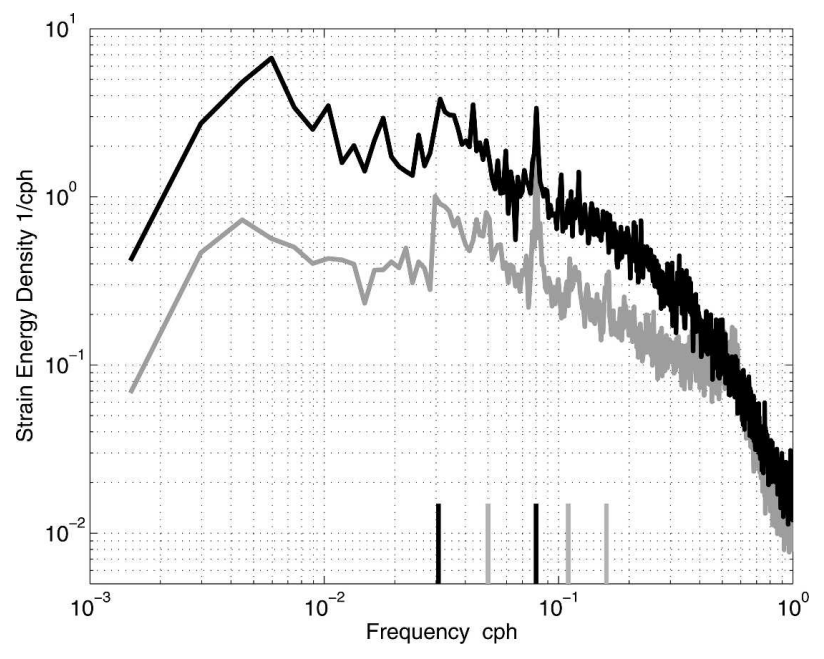

FIG. 13. Frequency spectra of strain about 3993-m (gray line) and 4648-m (black line) depth.

sity for differences across 10 and $25 \mathrm{~m}$ also differ by a factor of $\sim 3$.

Strain variance also increases with depth at the mooring site. Strain spectral energy densities about $4648 \mathrm{~m}$ exceed those about $3993 \mathrm{~m}$ by about a factor of 3 at all frequencies except SD where the estimates are comparable (Fig. 13). Both spectra exhibit a relative minimum in energy density around $0.02 \mathrm{cph}$, an upward step at $f$, and then an $\omega^{-1 / 2}$ dependence to the respective buoyancy frequency (with an SD peak superimposed).

Barotropic tidal currents, Polzin et al.'s (1997) hypothesized energy source for the enhanced finescale shears above the MAR in the Brazil Basin, modulate at fortnightly period due to the beating of the semidiurnal components. Fortnightly variability in finescale shear would be expected if 1) the small-scale internal waves responsible for the bulk of the shear variance were generated by the barotropic tide responding to the rough ocean bathymetry, 2) the resultant small-scale waves were able to propagate from their generation regions to the measurement site, and 3) those distances were sufficiently short that differences in wave intensities can be observed before the waves relax back to background intensity. Duda (2004) reported fortnightly modulation in his Shearmeter data from $2850 \mathrm{~m}$; evidence of fortnightly modulation in the current-meter data is more tenuous.

Suggestive of fortnightly modulation, the shear magnitude and strain spectra based on the VACM data exhibit greatest energy density around 2-week period (a feature visually enhanced by the lower energy densities at the fundamental frequency that are influenced by the windowing/detrending and strain-estimation procedures). However, most of the variance derives from 

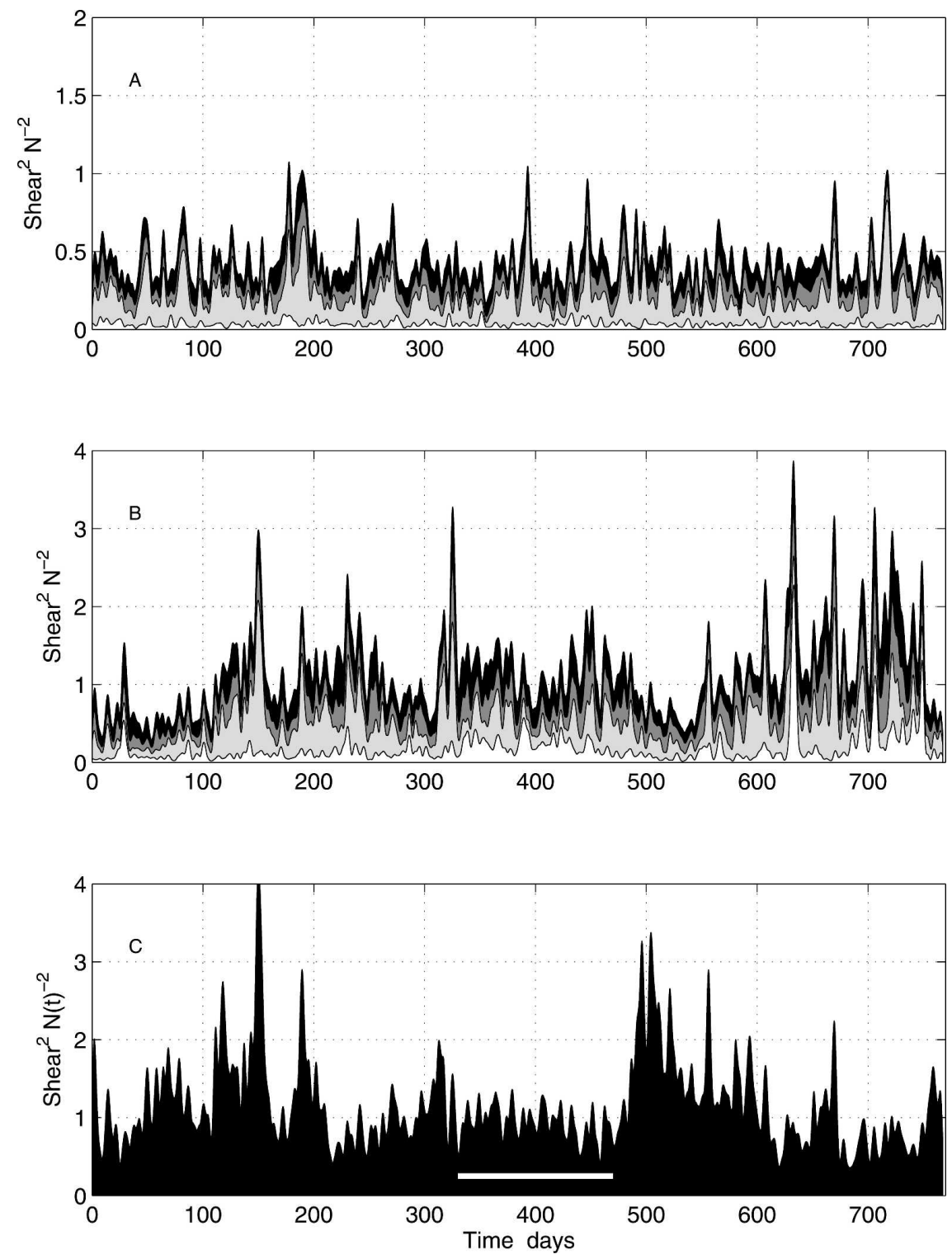

FIG. 14. Time series of shear variance normalized by $N^{2}$ : Estimates about (a) 2947 and (b) $4648 \mathrm{~m}$, partitioned into subinertial (white), near-inertial (light gray), near-semidiurnal (dark gray), and high-frequency (black) bands (see text). The normalization in (a) and (b) is with the time-mean $N^{2}$ from each level. (c) The time series of superinertial variance about $4648 \mathrm{~m}$ normalized by the time-varying $N^{2}$. The subsection marked with the white bar most clearly indicates fortnightly modulation.

motions at higher frequencies. Looking in greater detail, shear magnitude about 2947 and $4648 \mathrm{~m}$ was estimated in the time domain using the full velocity time series as well as the bandpassed records (Fig. 14). Total shear from the two levels is seen to vary on a variety of time scales; no dominant period is visually evident. Total shear is reasonably stationary about 2947 m (in comparison to the deeper record), varying by a factor of $\sim 4$. The autocorrelation function of the cosine-window fil- tered shear variance about $2947 \mathrm{~m}$ decays rapidly with lag, falling to below 0.2 at a lag of 5 days with a microscale [defined in terms of the curvature of the autocorrelation function at zero lag; Tennekes and Lumley (1972, p. 211)] of 4.2 days. The autocorrelogram has a secondary maximum around a lag of 14 days but its magnitude is only 0.16 . A run test finds 103 intervals in the 767-day record within which successive estimates of the shear variance are either above or below the mean. 
The average run length is thus $\sim 7.5$ days, suggesting, for an oscillatory signal, an average period of $\sim 15$ days.

The shear variance time series about $4648 \mathrm{~m}$ is more variable (Fig. 14b), ranging by a factor of 8 . Some of this variability is due to changes in the stratification; as demonstrated in Fig. 7c, scaling shear variance with the time-varying $N^{2}$ yields extended periods in which the internal- wave-band shear variance is reasonably stationary. The 140-day period marked in Fig. 14c is particularly regular. The autocorrelation function of shear magnitude for this interval rings with secondary peaks having amplitudes of $\pm 0.3-0.4$. The first positive lobe of the autocorrelogram occurs at a lag just under 15 days. High-pass filtering the whole record in Fig. 14c at 50 days yields a reasonably regular series consisting of 116 runs in which successive estimates are either above or below zero: average run length is 6.6 days. However, the autocorrelation function for this heavily manipulated record, while oscillatory, has its first positive sidelobe at a lag of $\sim 36$ days.

Correlation between the finescale shear variance and the amplitude of the surface tide was investigated. The tidal model time series of barotropic kinetic energy was derived and filtered with the same 7-day cosine window as was applied to the finescale shear variance estimates. Maximum positive lag correlation between the shear variance about $2947 \mathrm{~m}$ and the tidal kinetic energy for the full record was only 0.15 (not significantly different from zero at the 0.05 level assuming a decorrelation time scale of 7 days) obtained at a lag of $\sim 6$ days. Similarly about $4648 \mathrm{~m}$, maximum lag correlation between buoyancy-scaled shear variance and the tidal kinetic energy is not significantly different from zero $(0.1$ at a lag of $\sim 4$ days) based on the 50-day high-passed record. A marginally significant correlation of 0.46 is obtained at a 7-day lag for the 140-day segment marked in Fig. 14c. These lags are considerably longer than the 3 day lag between surface tide kinetic energy and depth-averaged turbulent dissipation reported by Ledwell et al. (2000) but comparable to that estimated by Duda (2004).

Returning to Fig. 14, it is noted that the shear variance in the near-inertial band exceeded that in two higher-frequency bands on average and much of the variability in the total shear variance derived from the near-inertial band. The semidiurnal and high-frequency bands contributed comparable shear variance while the low-frequency currents contribute the least to the total shear variance. Synoptically, there were just a handful of times over the 2-yr record from the VACMs about $4648 \mathrm{~m}$ when low-frequency currents made a significant contribution to the total shear squared. Low-frequency shear never made a sizable contribution about $2947 \mathrm{~m}$.

\section{d. Temperature (density) inversions and Richardson number statistics}

Whereas virtually no potential temperature (or inferred potential density) inversions were observed over the 25-m VACM separation about $3993 \mathrm{~m}$ (just three half-hour samples in two years, Fig. 6a), 3.5\% of the samples about $4648 \mathrm{~m}$ had warmer water below colder (Fig. 7a). Accuracy of the VACM temperature data is a concern here as fully one-third of the temperature difference estimates between the VACMs at 4635 and $4660 \mathrm{~m}$ are less than $0.01^{\circ} \mathrm{C}$ ( 2 times the quoted uncertainty of the instrument) whereas just $1 \%$ of the temperature difference estimates about $3993 \mathrm{~m}$ are this small. Notably, however, the shapes of the two temperature difference histograms (which are insensitive to temperature offsets in one or both instruments in a pair) are markedly different (not shown). In particular, the temperature difference histogram for the instruments about $4648 \mathrm{~m}$ is more asymmetric and peaked relative to that for the instruments about $3993 \mathrm{~m}$ (skewness of 1.29 versus 0.73 ; kurtosis of 5.14 versus 3.95 ). This suggests different behavior was documented at the two levels despite the small signal sizes. In the following, the question of temperature uncertainty is set aside.

Eriksen (1998), analyzing moored temperature data from the flank of Fieberling Guyot, related inversions to the turbulent mixing intensity through inferred changes in potential energy. Following Eriksen, relative to a final state in which the water column between two current meters (vertical distance of $d$ ) is homogenized in density, the available potential energy of a given overturn $i$ per unit mass $(P)$ is $P=\operatorname{Im}\left(N_{i}\right)^{2} d^{2} / 12$. Assuming a time scale for overturn collapse of $\operatorname{Im}\left(N_{i}\right)^{-1}$, the time rate of change in potential energy per unit mass is $P_{t}=\operatorname{Im}\left(N_{i}\right)^{3} d^{2} / 12$, and the effective diapycnal diffusivity is $K_{z}=\left\langle P_{t}\right\rangle N^{-2}$. Applying this formalism to the VACM data about $4648 \mathrm{~m}$, assuming zero rate of change in potential energy for the samples that are stably stratified, we find $\left\langle P_{t}\right\rangle=4.1 \times 10^{-11} \mathrm{~W} \mathrm{~kg}^{-1}$ and $K_{z}=0.86 \times 10^{-4} \mathrm{~m}^{2} \mathrm{~s}^{-1}$. The virtual absence of inversions about $3993 \mathrm{~m}$ likely indicates that the turbulent overturns at this level are much smaller than the 25-m separation between the VACMs. For comparison, analysis of tracer dispersion by Ledwell et al. (2000) yielded a diapycnal diffusivity estimate of $3 \times 10^{-4}$ $\mathrm{m}^{2} \mathrm{~s}^{-1}$ near $4000 \mathrm{~m}$ (level of the tracer injection) increasing to $8 \times 10^{-4} \mathrm{~m}^{2} \mathrm{~s}^{-1}$ about $4500 \mathrm{~m}$. Note however that these tracer-based estimates represent spatial (isopycnal) averages encompassing more intense mixing zones east of the mooring site and closer to the bottom. Estimates of the turbulent kinetic energy dis- 
sipation rate based on data collected within fracture zones increase from around $5 \times 10^{-10} \mathrm{~W} \mathrm{~kg}^{-1}$ at 4000 $\mathrm{m}$ to order $1 \times 10^{-9} \mathrm{~W} \mathrm{~kg}^{-1}$ at $4500 \mathrm{~m}$ (Ledwell et al. 2000; St. Laurent et al. 2001). For typical stratified turbulence, the corresponding turbulent buoyancy fluxes are about a factor of 5 smaller.

An alternate estimate of the turbulent mixing intensity is provided by the Richardson number, $\mathrm{Ri}=N^{2} S^{-2}$ where $S^{2}=u_{z}^{2}+v_{z}^{2}$. The VACM pair about $4648 \mathrm{~m}$ had $\mathrm{Ri}<1 / 4$ for $9.2 \%$ of the half-hourly samples in the 2 -yr time series. These occurred intermittently throughout the record with each supercritical $\mathrm{Ri}$ event lasting at most a couple of hours. The Ri probability density distribution (Fig. 15) shows the characteristic peak at $\mathrm{Ri}<$ 1 and long tail of large Ri values. A scatterplot of $N^{2}$ versus $S^{2}$ (not shown) fails to clearly indicate the cutoff at $\mathrm{Ri}=1 / 4$ that has been seen in other records (e.g., Eriksen 1978). Rather, the distribution is largely bound by the line $N^{2}=0.25 S^{2}-0.3 \times 10^{-6} \mathrm{~s}^{-2}$. As opposed to Eriksen's (1978) example, the absence of a cutoff at $\mathrm{Ri}=1 / 4$ might be because the $25-\mathrm{m}$ current-meter separation distance was well within the range of the turbulent overturn heights.

Kunze et al. (1990) developed a parameterization for the turbulent dissipation and mixing due to shear instability in low Ri events. In this model, the excess kinetic energy relative to a state in which the Richardson number is relaxed to the neutral value of $1 / 4$ is available for mixing on the time scale for the growth of KelvinHelmholz billows. The model's time rate of change in potential energy is thus: $P_{t}=\Gamma d^{2}\left\langle\left(S^{2}-4 N^{2}\right)(S-2 N)\right\rangle /$ 96, where $\Gamma$ is the mixing efficiency. Polzin (1996) explored the dependencies of this parameterization on the vertical differencing scale and the neutral $\mathrm{Ri}$ value and found that for a differencing interval comparable to the finescale cutoff scale in the vertical wavenumber shear spectrum, the Kunze et al. formulation with neutral $\mathrm{Ri}=1 / 4$ underestimated the observed turbulent dissipation by a factor of 3-5. Applying Kunze et al.'s expression to the VACM data about $4648 \mathrm{~m}$ with $\Gamma=$ 0.2 and a neutral $\mathrm{Ri}=1 / 4$ (where $P_{t}$ is set to zero for those estimates in which $\mathrm{Ri}>1 / 4$ or $\mathrm{Ri}<0$ ) yields a record-mean estimate of $\left\langle P_{t}\right\rangle=1.3 \times 10^{-10} \mathrm{~W} \mathrm{~kg}^{-1}$ and $K_{z}=2.7 \times 10^{-4} \mathrm{~m}^{2} \mathrm{~s}^{-1}$. These mean values are reasonably close to the estimates based on the microstructure data, particularly when the tendency for model underestimation that Polzin (1996) noted is considered. Reassuringly, times when density inversions were observed (and nonzero buoyancy flux estimates were obtained from the overturn model) tended to occur around the times when $\mathrm{Ri}<1 / 4$ (when the $\mathrm{Ri}$ model returned nonzero flux estimates) (Fig. 16). Those flux events inferred at times of low Ri that did not corre-

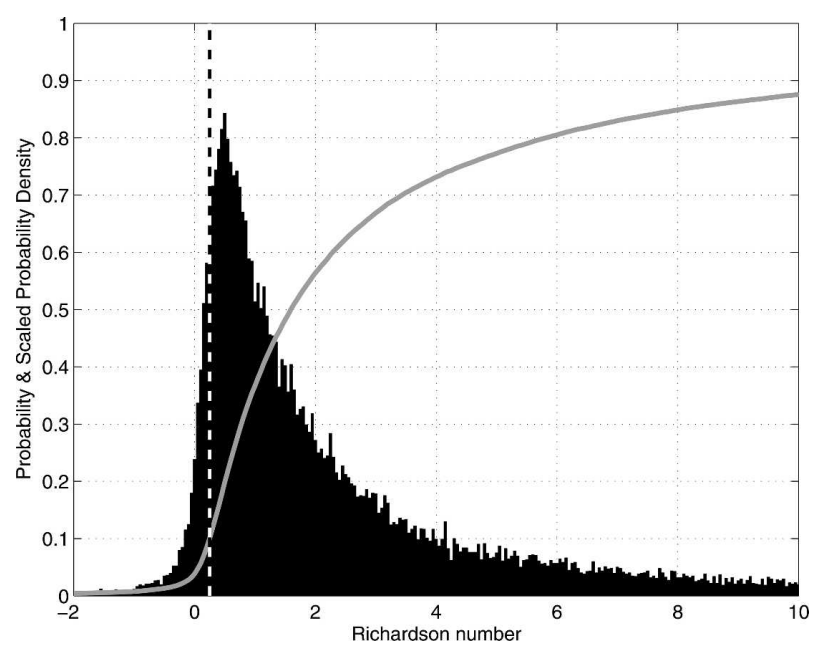

FIG. 15. The probability (gray curve) and scaled probability density (black bars) distributions of Ri based on data about 4648-m depth. The vertical dashed line marks $\mathrm{Ri}=1 / 4$.

spond to times of density inversions might be rationalized by arguing that the overturns at those times did not extend to $25 \mathrm{~m}$ in vertical extent. The mooring's limited vertical resolution for quantifying overturning scales might also account for the differences in the average buoyancy flux and $K_{z}$ from the two approaches.

\section{Discussion}

Perhaps the biggest surprise in the BBTRE mooring data is the contribution of near-inertial motions to the finescale shear field. While significant velocity and shear variance was observed at tidal frequencies, those motions by no means dominated the total shear magnitude, and appeared to only rarely modulate the total shear variance despite obvious fortnightly modulation of the tidal-band velocities. Internal wave-wave interactions that redistribute energy in both frequency and wavenumber may be responsible. Hibiya et al. (2002) and MW explored the nonlinear redistribution of internal wave energy within the frequency-wavenumber spectrum, highlighting in particular the role of the parametric subharmonic instability (PSI) at low latitudes. Equatorward of latitude $28.9^{\circ}$ (where the inertial frequency is $1 / 2 M_{2}$ ), PSI-type nonlinear interactions can transfer energy from semidiurnal-frequency waves to a pair of free waves at half the frequency and smaller vertical wavelength. While the moored velocity and shear spectra show enhanced energy density at nearinertial frequency, no obvious peak is observed right at $1 / 2 M_{2}$ as might be expected from a classical PSI interaction. In contrast to the present data, Carter and Gregg (2006) offer compelling evidence in data col- 


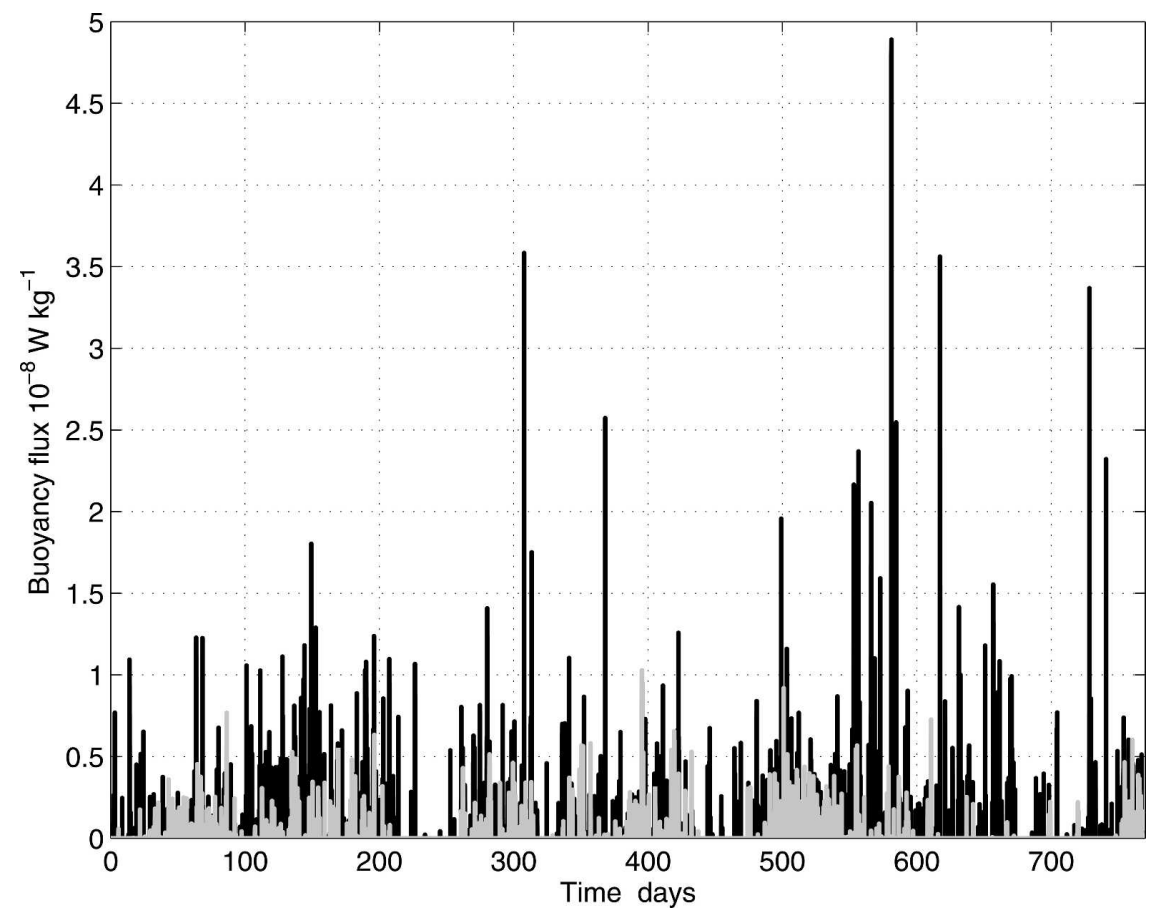

FIG. 16. Time series of turbulent vertical buoyancy flux about $4648 \mathrm{~m}$ based on potential temperature inversions (gray bars) and Richardson number (black bars). Nonzero flux estimates are derived only for times of temperature inversions in the first case and when $0<\mathrm{Ri}$ $<1 / 4$ in the second.

lected about Kaena Ridge (in close proximity to generation sites for internal tidal motions) for near-diurnal internal wave forcing via a PSI-like wave-wave interaction. However, they note that, at large amplitude, the PSI weak wave interaction theory may not be applicable.

In the early stages of MW's simulations of a narrowband bottom source of $M_{2}$ waves at latitude $21^{\circ} \mathrm{S}$, a resonant triad interaction develops involving the source waves with waves at frequencies slightly above and slightly below $1 / 2 M_{2}$. This pair of internally generated waves have opposing vertical phase velocity, reminiscent of PSI, but the one at lower frequency has longer vertical wavelength than the $M_{2}$ component; J. A. MacKinnon (2005, personal communication) speculated if the near-inertial motions observed about 2947and 4648-m depth in the BBTRE mooring data might be the product of triad interactions with the internal tide, but pointed out that for an interaction with an upgoing internal tide, the upgoing wave should have a smaller wavelength than the downgoing wave (opposite to what is estimated).

Later in the MW simulation (stated to be about a month), the model spectrum broadens as other triad interactions develop and a steady state is achieved between the narrowband bottom energy source, a vertical energy flux at the top of the simulation domain $(60 \%$ of the source power) and dissipation within the domain ( $40 \%$ of the source). These subsequent nonlinear interactions appear to preferentially transfer energy to lower frequencies such that, in steady state at vertical distances of $700 \mathrm{~m}$ and greater above the bottom, most of the model's superinertial variance lies at frequencies just above $f$, with small spectral peaks at $M_{2}$ and just above $1 / 2 M_{2}$ (see Fig. 4 in MW). While the large contribution by near-inertial motions in the simulation is similar in character to the BBTRE mooring data, semidiurnal shears remain significant in the data even about 2947-m depth.

Alternatively, Garrett (2001) calls attention to the possible importance of surface-generated inertial wave reflection and scattering from rough bathymetry such as the MAR. Perhaps near-critical reflection from ridge crests accounts for the preponderance of upgoing finescale inertial motion about $2947 \mathrm{~m}$ and downgoing energy about $4648 \mathrm{~m}$ as sketched in Fig. 2c, with subsequent energy loss of the latter through sidewall scattering and/or breaking responsible for the weaker inertial motions at $4878 \mathrm{~m}$. In this vein, Duda (2004) reports that two of the four largest peaks in the Shearmeter estimates of shear to the fourth power occurred around times of atmospheric low pressure events. As Alford 
(2001) and others have reported, wind energy input to upper-ocean inertial motions is highly seasonal (strongest energy input in winter). However, no obvious seasonality is evident in the moored shear variance time series of Fig. 14.

The weak fortnightly modulation of shear variance in the BBTRE records was also surprising. The contribution of semidiurnal motions to the total shear field about $4648 \mathrm{~m}$ might have been suppressed by shadowing effects. As shown in Fig. 2c, the ray trajectories for internal waves at semidiurnal frequency radiating or reflecting from the (subcritical) sloping sides of the fracture zone pass above the VACM pair about $4648 \mathrm{~m}$. Similarly, SD ray trajectories emanating from the transverse fault features east and west of the mooring site pass above these current meters. Thus the deepest four VACMs on the mooring appear to have been effectively shielded from much of the locally generated semidiurnal internal wave energy. (Begging the question of their energy source, lower-frequency waves radiating from the sides of the fracture zone and the transverse faults east and west of the mooring could propagate directly to the deep current meters.) The VACMs about $2947 \mathrm{~m}$ may be sufficiently distant from the bottom that dispersion, nonlinear interactions, and dissipation obscure any fortnightly modulation in internal tide generation.

The subinertial currents within the valley at the BBTRE mooring site were stronger than expected. Thurnherr et al. $(2002,2005)$ highlight the hydraulic behavior of such low-frequency flows responding to bathymetric structures and the subsequent turbulent mixing within MAR valleys. Radiating internal lee waves might also be expected in response to lowfrequency flow over rough bathymetry. The contribution by internal lee waves to the finescale shear variance observed by the VACMs is unclear. A comparison of Figs. $4 \mathrm{~b}$ and $14 \mathrm{~b}$ hints at a relationship between the low-frequency flow and low-frequency shear variance about $4648 \mathrm{~m}$ : larger subinertial shear variance often occurs at times of stronger low-frequency flow. But lacking vertical resolution, we cannot determine if the shear enhancement is due to small-vertical-scale stationary (lee) waves or is a characteristic of the largescale, low-frequency flow. In any event, the low-frequency shears make relatively small contribution to the total shear, and the variability of the total shear variance (and the superinertial shear variance normalized by the time-varying buoyancy frequency) bears little relationship to the strength of the low-frequency currents.

It is gratifying that the average diapycnal diffusivity inferred from the Richardson number estimates and temperature inversions about $4648 \mathrm{~m}$ were of the same order of magnitude as those based on the turbulent dissipation observations obtained on the first two BBTRE cruises and from the rate of tracer dispersion. The mooring data thus add additional support to the idea that energetic finescale motions above rough bathymetry support enhanced turbulent diapycnal mixing in these regions. However, the BBTRE mooring data were not able to clearly identify the specific mechanisms responsible for the finescale shears at the site. Akin to the Shearmeter records, the BBTRE mooring data demonstrate that total shear is modulated on a host of time scales (not simply fortnightly period). Dispersion, wave-wave interactions, and wave breaking can effectively obscure sources of finescale energy. Observations at other sites with the measurements at greater vertical resolution over a greater vertical span and that allow estimation of internal wave energy fluxes might shed light on the question.

Acknowledgments. This paper is dedicated to Susan Tarbell and Carol Alessi, both of whom assisted with the reduction and processing of the current-meter data analyzed here. Their loss is still keenly felt. The author thanks T. Duda, J. Ledwell, J. MacKinnon, K. Polzin, and A. Thurnherr for critical comments on earlier drafts. The research presented in this manuscript was supported by the U.S. National Science Foundation through Grants OCE-9415589 and OCE-0217075 to the Woods Hole Oceanographic Institution. Any opinions, findings, and conclusions or recommendations expressed in this material are those of the author and do not necessarily reflect the views of the National Science Foundation.

\section{REFERENCES}

Alford, M. H., 2001: Internal swell generation: The spatial distribution of energy flux from the wind to mixed layer nearinertial motions. J. Phys. Oceanogr., 31, 2359-2368.

Bell, T. H., 1975: Topographically generated internal waves in the open ocean. J. Geophys. Res., 80, 320-327.

Carter, G. S., and M. C. Gregg, 2006: Persistent near-diurnal internal waves observed above a site of $M_{2}$ barotropic-tobaroclinic conversion. J. Phys. Oceanogr., 36, 1136-1147.

Duda, T. F., 2004: Finescale shear at 1660 and 2850 dbar over the Mid-Atlantic Ridge in the eastern Brazil Basin. J. Phys. Oceanogr., 34, 1281-1292.

Egbert, G. D., and S. Y. Erofeeva, 2002: Efficient inverse modeling of barotropic ocean tides. J. Atmos. Oceanic Technol., 19, 183-204.

—_, A. F. Bennett, and M. G. G. Foreman, 1994: TOPEX/ Poseidon tides estimated using a global inverse model. $J$. Geophys. Res., 99, 24 821-24 852.

Eriksen, C. C., 1978: Measurements and models of fine structure, 
internal gravity waves and wave breaking in the deep ocean. J. Geophys. Res., 83, 2989-3009.

_ , 1998: Internal wave reflections and mixing at Fieberling Guyot. J. Geophys. Res., 103, 2977-2994.

Garrett, C., 2001: What is the "near-inertial" band and why is it different from the rest of the internal wave spectrum? $J$. Phys. Oceanogr., 31, 962-971.

_ waves. Deep-Sea Res., 19, 823-832.

Gregg, M. C., 1989: Scaling turbulent dissipation in the thermocline. J. Geophys. Res., 94, 9689-9698.

Henyey, F. S., R. Wright, and S. M. Flatte, 1986: Energy and action flux through the internal wave field: An eikonal approach. J. Geophys. Res., 91, 8487-8495.

Hibiya, T., M. Nagasawa, and Y. Niwa, 2002: Nonlinear energy transfer within the oceanic internal wave spectrum at mid and high latitudes. J. Geophys. Res., 107, 3207, doi:10.1029/ 2001JC001210.

Kunze, E., A. J. Williams III, and M. G. Briscoe, 1990: Observations of shear and vertical stability from a neutrally buoyant float. J. Geophys. Res., 95, 18 127-18 142.

— , L. K. Rosenfeld, G. S. Carter, and M. C. Gregg, 2002: Internal waves in Monterey Submarine Canyon. J. Phys. Oceanogr., 32, 1890-1913.

Ledwell, J. R., E. T. Montgomery, K. L. Polzin, L. C. St. Laurent, R. W. Schmitt, and J. M. Toole, 2000: Evidence for enhanced mixing over rough topography in the abyssal ocean. Nature, 403, 179-182.

Leeman, K. D., and T. B. Sanford, 1975: Vertical energy propagation of inertial waves: A vector spectral analysis of velocity profiles. J. Geophys. Res., 80, 1975-1978.

Levine, M. D., 2002: A modification of the Garrett-Munk internal wave spectrum. J. Phys. Oceanogr., 32, 3166-3181.

MacKinnon, J. A., and K. B. Winters, 2003: Spectral evolution of bottom-forced internal waves. Near-Boundary Processes and Their Parameterization: Proc. 13th 'Aha Huliko'a Hawaiian Winter Workshop, Honolulu, HI, University of Hawaii at Manoa, 73-83.

Müller, P., and N. Xu, 1992: Scattering of oceanic internal waves off random bottom topography. J. Phys. Oceanogr., 22, 474488.

Munk, W., 1981: Internal waves and small-scale processes. Evolution of Physical Oceanography: Scientific Surveys in Honor of Henry Stommel, B. A. Warren and C. Wunsch, Eds., The MIT Press, 264-291.

Pinkel, R., and S. Anderson, 1997: Shear, strain and Richardson number variation in the thermocline. Part I: Statistical description. J. Phys. Oceanogr., 27, 264-281.

Polzin, K., 1996: Statistics of the Richardson number: Mixing models and finestructure. J. Phys. Oceanogr., 26, 1409-1425. , 2004a: A heuristic description of internal wave dynamics. $J$. Phys. Oceanogr., 34, 214-230.

- 2004b: Idealized solutions for the energy balance of the finescale internal wave field. J. Phys. Oceanogr., 34, 231-246.

_ J. M. Toole, and R. W. Schmitt, 1995: Finescale parameterizations of turbulent dissipation. J. Phys. Oceanogr., 25, 306 328.

— — - J. R. Ledwell, and R. W. Schmitt, 1997: Spatial variability of turbulent mixing in the abyssal ocean. Science, 276, 93-96.

Saunders, P. M., 1981: Practical conversion of pressure to depth. $J$. Phys. Oceanogr., 11, 573-574.

Smith, W. H. F., and D. T. Sandwell, 1997: Global seafloor topography from satellite altimetry and ship depth soundings. Science, 277, 1957-1962.

St. Laurent, L., and C. Garrett, 2002: The role of internal tides in mixing the deep ocean. J. Phys. Oceanogr., 32, 2882-2899.

_ J. M. Toole, and R. W. Schmitt, 2001: Buoyancy forcing by turbulence above rough topography in the abyssal Brazil Basin. J. Phys. Oceanogr., 31, 3476-3495.

Tennekes, H., and J. L. Lumley, 1972: A First Course in Turbulence. The MIT Press, 300 pp.

Thurnherr, A. M., K. J. Richards, C. R. German, G. F. Lane-Serff, and K. G. Speer, 2002: Flow and mixing in the Rift Valley of the Mid-Atlantic Ridge. J. Phys. Oceanogr., 32, 1763-1778.

- L. C. St. Laurent, K. G. Speer, J. M. Toole, and J. R. Ledwell, 2005: Mixing associated with sills in a canyon on the midocean ridge flank. J. Phys. Oceanogr., 35, 1370-1381. 